Article

\title{
Air-Quality Challenges of Prescribed Fire in the Complex Terrain and Wildland Urban Interface Surrounding Bend, Oregon
}

\author{
Colton Miller ${ }^{1}$, Susan $\mathrm{O}^{\prime} \mathrm{Neill}^{2, *}$, Miriam Rorig ${ }^{2}$ and Ernesto Alvarado ${ }^{1}$ (D) \\ 1 School of Environmental and Forest Sciences, University of Washington, Seattle, WA 98195, USA \\ 2 Pacific Northwest Research Station, U.S. Forest Service, Seattle, WA 98103, USA \\ * Correspondence: susan.oneill@usda.gov
}

Received: 18 July 2019; Accepted: 1 September 2019; Published: 3 September 2019

\begin{abstract}
Prescribed fires in forest ecosystems can negatively impact human health and safety by transporting smoke downwind into nearby communities. Smoke transport to communities is known to occur around Bend, Oregon, United States of America (USA), where burning at the wildland-urban interface in the Deschutes National Forest resulted in smoke intrusions into populated areas. The number of suitable days for prescribed fires is limited due to the necessity for moderate weather conditions, as well as wind directions that do not carry smoke into Bend. To better understand the conditions leading to these intrusions and to assess predictions of smoke dispersion from prescribed fires, we collected data from an array of weather and particulate monitors over the autumn of 2014 and spring of 2015 and historical weather data from nearby remote automated weather stations (RAWS). We characterized the observed winds to compare with meteorological and smoke dispersion models using the BlueSky smoke modeling framework. The results from this study indicated that 1-6 days per month in the spring and 2-4 days per month in the fall met the general meteorological prescription parameters for conducting prescribed fires in the National Forest. Of those, $13 \%$ of days in the spring and $5 \%$ of days in the fall had "ideal" wind patterns, when north winds occurred during the day and south winds did not occur at night. The analysis of smoke intrusions demonstrated that dispersion modeling can be useful for anticipating the timing and location of smoke impacts, but substantial errors in wind speed and direction of the meteorological models can lead to mischaracterizations of intrusion events. Additionally, for the intrusion event modeled using a higher-resolution 1-km meteorological and dispersion model, we found improved predictions of both the timing and location of smoke delivery to Bend compared with the $4-\mathrm{km}$ meteorological model. The 1-km-resolution model prediction fell within $1 \mathrm{~h}$ of the observed event, although with underpredicted concentrations, and demonstrated promise for high-resolution modeling in areas of complex terrain.
\end{abstract}

Keywords: Prescribed fire; particle matter smaller than $2.5 \mu \mathrm{m}\left(\mathrm{PM}_{2.5}\right)$; smoke; dispersion modeling; RAWS

\section{Introduction}

Forest management agencies are increasingly moving away from fire exclusion and toward policies that balance modified suppression with the use of prescribed fire to achieve multiple ecological objectives [1]. Therefore, predicting smoke impacts and, probably more importantly, determining meteorological conditions that reduce smoke impacts from prescribed fires is needed. Few studies addressed this [2,3]. There were comprehensive fuel, fire behavior, and smoke measurements on prescribed fires (e.g., Reference [4]). However, these data were not used to evaluate and improve smoke modeling systems, especially in terms of meteorological conditions. This research was completed in 
collaboration with the Deschutes National Forest (DNF) to investigate meteorological conditions around Bend, Oregon and evaluate smoke dispersion models with the goal of determining what is required to conduct prescribed fires in the area without causing excessive impacts on nearby communities. The geography of Bend and the DNF provides a complicated environment for prescribed fire from a smoke management perspective due to the complex terrain and the location of burn units typically being upslope from populated areas.

Wildland fire is a naturally occurring ecological process, and many forests in the western United States (US) were shaped by the periodic occurrence of fire [5,6]. A history of timber harvesting, grazing, and fire suppression altered the role fire played on the landscape and, in some cases, caused shifts in forest structure and composition [7]. These changes led to widespread fuel accumulations which can enhance the intensity and severity of wildfires (e.g., Reference [8]). Forest managers use prescribed fire to improve forest health and create a diversity of plant and wildlife habitat $[9,10]$. Additionally, prescribed fires reduce forest fuels and mitigate the intensity and effects of wildfires [11]. However, planning prescribed fires presents challenges in avoiding undesired consequences to communities such as smoke and visibility.

Exposure to the smoke generated from forest fires (wild and prescribed) has negative health impacts [12-14], and the associated costs are substantial [15]. While woodsmoke is known to contain many toxic pollutants [16], particles smaller than $2.5 \mu \mathrm{m}$ in aerodynamic diameter $\left(\mathrm{PM}_{2.5}\right)$ are a major concern owing to their health impacts [17] and ability to transport over long distances [16]. The US Environmental Protection Agency (EPA), through the Clean Air Act of 1970, set standards as defined by the National Ambient Air Quality Standards (NAAQS) to protect the public [18]. The maximum allowable level of $\mathrm{PM}_{2.5}$ averaged over a 24 -h period is $35 \mu \mathrm{g} \cdot \mathrm{m}^{-3}$. States may also implement their own regulations in addition to the NAAQS specified by the EPA.

The relationship among winds, fire behavior, vegetation, and smoke dispersion is especially difficult in areas of complex terrain. Wind speed and direction are affected by topography, and vegetation moisture can change at time scales of hours, minutes, and even seconds [19]. Additionally, complex topography can directly affect fire behavior and smoke transport $[10,20]$. Surface winds may similarly be affected by variations in vegetation cover. Understanding how fuels, vegetation, fire, topography, and wind patterns interact for a particular region can improve the ability to predict how and where smoke will disperse.

The DNF, located in the Cascade Mountains west of Bend, uses prescribed fire at the wildland-urban interface (WUI) to meet management objectives while protecting the public's quality of life in nearby communities. A major constraint is the potential for smoke from prescribed fires to reach nearby communities. The state of Oregon's administrative rules include regulations regarding smoke intrusions, where a "smoke intrusion" is defined as the verified entrance of ground-level smoke from prescribed fires into designated smoke-sensitive areas [21]. The restrictions are characterized by the 1-h average $\mathrm{PM}_{2.5}$ concentration above the previous 3-h average $\mathrm{PM}_{2.5}$ concentration.

The US Forest Service AirFire research team collaborated with the DNF on a field measurement and modeling project to study the complex interaction of fuels, fire, topography, and wind patterns to better understand smoke intrusions from prescribed fires. During the study, smoke from six prescribed fires intruded into Bend, with 1-h $\mathrm{PM}_{2.5}$ concentrations ranging from $11 \mu \mathrm{g} \cdot \mathrm{m}^{-3}$ to $245 \mu \mathrm{g} \cdot \mathrm{m}^{-3}$. Both wildfires and prescribed fires were used for large-scale evaluation of air-quality prediction systems that include wildfire emissions (e.g., References [22-24]). However, the current study is unique because few case studies synthesized meteorological conditions, smoke dispersion modeling, and ground-based observations, especially for prescribed fires. 
The goal for this study was to characterize the conditions under which smoke intrusions occur and to assess the ability of smoke dispersion modeling to predict the timing and direction of smoke transport from prescribed fires. To investigate the spatial variability in meteorological conditions and analyze smoke dispersion in the area surrounding Bend, we deployed portable $\mathrm{PM}_{2.5}$ and meteorological measurement stations for approximately nine months during the prescribed fire seasons. The objectives of this study were to (1) characterize the frequency of acceptable meteorological conditions for prescribed fire, (2) describe seasonal wind patterns and identify circumstances that may avoid smoke intrusions into populated areas, and (3) evaluate existing meteorological and smoke dispersion modeling performance during smoke intrusions via measured and modeled $\mathrm{PM}_{2.5}$ data. This is one of the few studies gathering a comprehensive dataset of meteorological measurements, $\mathrm{PM}_{2.5}$ measurements, and documented burn information. The results of this research will improve our understanding of smoke dispersion modeling, support the planning of prescribed fires, and ultimately lead to better predictions and fewer smoke intrusions.

\section{Methods}

\subsection{Study Area}

The study area was located in Deschutes County, Oregon, near the cities of Sisters, Bend, and Sunriver (Figure 1). The city of Bend, with a population of approximately 86,238 people (2015 estimate), is designated as a "smoke-sensitive receptor area"; thus, it receives the highest level of protection under the state's smoke management plan to prevent smoke from prescribed fire in forestlands from being carried to or accumulating in the area [25]. Both Bend and Sisters, along with all the prescribed fire locations in this study, fall within the Community Wildfire Protection Plan (CWPP) WUI boundary [26]. This means the area contains or is adjacent to an at-risk community identified by CWPP where structures or human development meet or intermingle with wildland vegetation.

The DNF lies approximately $6 \mathrm{~km}$ to the west of Bend. It contains portions of the Cascade Range but is mainly on the eastern slopes and foothills of the Cascades. The terrain in the DNF has numerous mountains, buttes, and peaks including Three Sisters, Broken Top, Broken Hand, Paulina Peak, Ball Butte, Tumalo Mountain, and Mount Bachelor, as well as others. Much of the topography is made up of draws in an eastern/northeastern direction coming down off the Cascade Range's eastern slopes and foothills. The elevation ranges from 593 to $3153 \mathrm{~m}$ with an average of $1485 \mathrm{~m}$, while Bend and Sisters are at $1104 \mathrm{~m}$ and $970 \mathrm{~m}$, respectively. Slopes range from 0 to $649 \%$ with an average of $10 \%$. Two major waterways, the Deschutes River and Whychus Creek, flow toward the northeast through Bend and Sisters, respectively.

Annual precipitation in Bend is about $288 \mathrm{~mm} \cdot \mathrm{year}^{-1}$, with the majority of precipitation occurring between November and February (Western Regional Climate Center; http://www.wrcc.dri.edu). The climate is classified as moist subtropical mid-latitude climate with a dry and warm summer season according to the Köppen climate classification. The vegetation in the area consists of Douglas fir, Ponderosa pine, Lodgepole pine, juniper, and savanna sagebrush. Prescribed fire in the DNF is typically conducted in the spring (April-June) and fall (September-November) months, and wildfires are a concern during the summer months (July, August, and into September). 

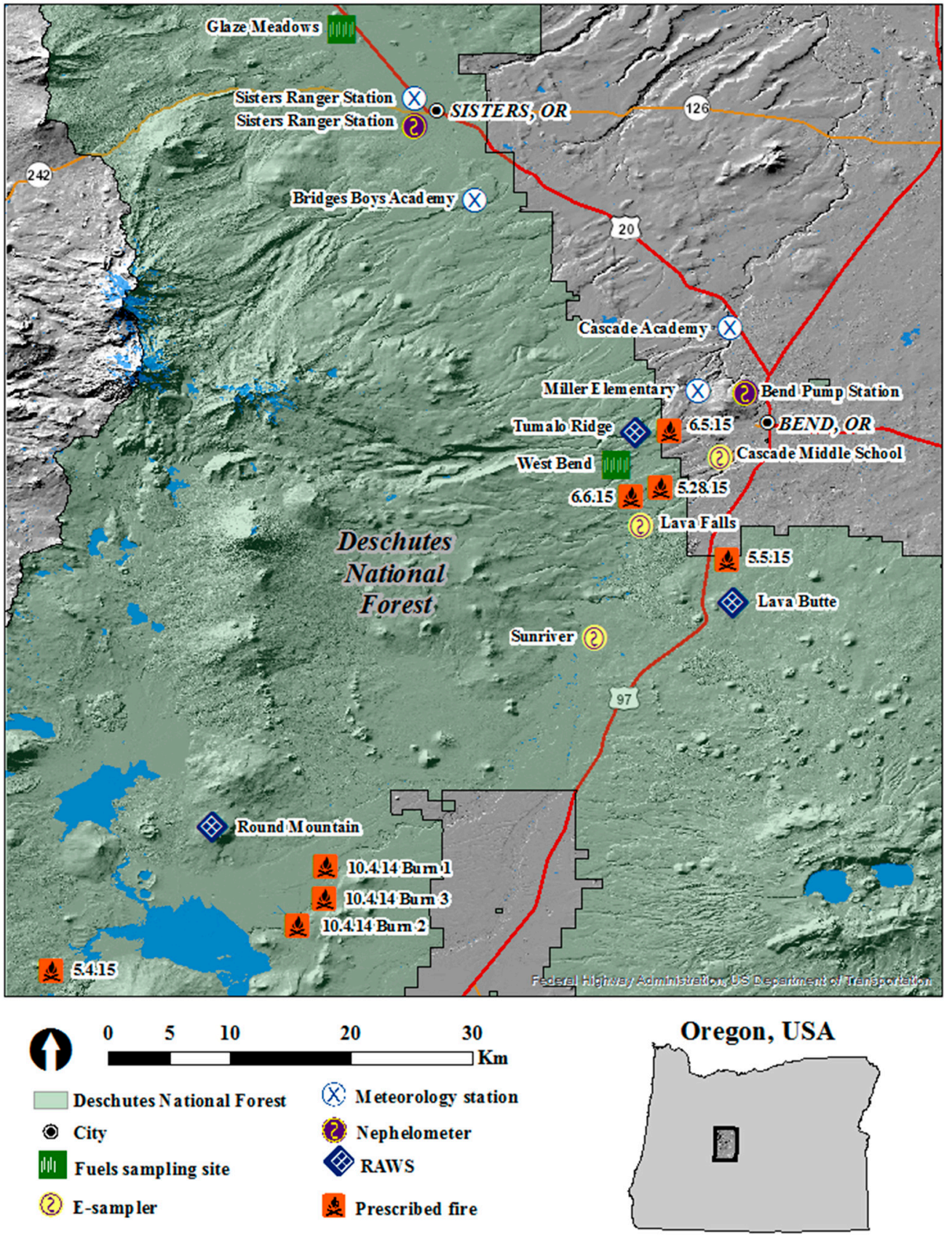

Figure 1. Map of study area in and around Bend, Oregon, showing locations of fuel sampling sites, co-located particle matter smaller than $2.5 \mu \mathrm{m}\left(\mathrm{PM}_{2.5}\right)$ and meteorological monitors (E-samplers), portable weather stations (WatchDog meteorological measurement stations), remote automated weather station (RAWS) sites, and prescribed fire locations.

\subsection{Acceptable Burn Days}

To determine how frequently land managers can expect conditions that are favorable for prescribed fire, we compiled the number of days fuel and meteorological parameters met conditions appropriate for prescribed fire ignition (Table 1). Although meteorological constraints may vary by fuel type or the spatial context of a burn unit, these values were provided by forest managers working in the DNF and reflected general weather constraints commonly used in the area. The days were identified by data measured and calculated from remote automated weather stations (RAWS) in the area, and included temperature, relative humidity (RH), wind speed, and 1-h, 10-h, and 100-h dead fuel moistures. We 
used Fire Family Plus v4.2, a software system for summarizing and analyzing historical daily fire weather observations [27], to identify days meeting the acceptable burn conditions. We analyzed data from three RAWS located in the study area maintained by the DNF and the Western Regional Climate Center (WRCC). These are permanently located stations with weather sensors located approximately $6 \mathrm{~m}$ above ground level and are typically placed in locations suitable for monitoring fire danger.

Table 1. Common meteorological parameters for prescribed fires conducted on the Deschutes National Forest.

\begin{tabular}{lccc}
\hline \multicolumn{1}{c}{ Parameter } & Low & High & $\begin{array}{c}\text { Minimal Acceptable } \\
\text { Moisture Parameters }\end{array}$ \\
\hline Air Temperature $\left({ }^{\circ} \mathrm{C}\right)$ & 4.4 & 26.7 & - \\
Relative humidity $(\%)$ & 20 & 40 & - \\
Mid-flame wind speed $\left(\mathrm{m} \cdot \mathrm{s}^{-1}\right)$ & 0 & 3.6 & 5 \\
1-h fuel moisture $(\%)$ & 5 & 10 & 6 \\
10-h fuel moisture (\%) & 6 & 12 & 7 \\
100-h fuel moisture $(\%)$ & 7 & 14 & 15 \\
1000-h fuel moisture $(\%)$ & - & - & 30 \\
Live fuel moisture $(\%)$ & - & - & \\
\hline
\end{tabular}

Daily fire weather observations (1:00 pm. Pacific Standard Time (PST)) from the Tumalo Ridge RAWS (7 km west of Bend at an elevation of $1220 \mathrm{~m}$; Bend elevation is $1105 \mathrm{~m}$ ), Lava Butte RAWS (15 km south of Bend at an elevation of $1344 \mathrm{~m}$ ), and Round Mountain RAWS (47 km southwest of Bend at an elevation of $1798 \mathrm{~m}$ ) were used to determine if burning would be within prescription for the days in the period from 2006-2015 (see Table 2 for a list of instrument locations and details). Data were assessed individually for each station and means calculated by month. Midflame wind speeds were estimated using wind adjustment factors provided in Andrews [19].

Table 2. Meteorological stations and smoke monitor locations for Spring 2015. Locations are listed from north to south. WX = WatchDog meteorological measurement station (wind speed, wind direction); $\mathrm{PM}_{2.5}=$ Met One Instruments, Inc. E-Sampler (particle matter smaller than $2.5 \mu \mathrm{m}\left(\mathrm{PM}_{2.5}\right)$ concentration, wind speed, wind direction); RAWS = remote automated weather station (temperature, relative humidity, wind speed, wind direction); nephelometer = Radiance Research M903 nephelometer ( $\mathrm{PM}_{2.5}$ concentration); $\mathrm{N}=$ north; $\mathrm{W}=$ west; $\mathrm{S}=$ south.

\begin{tabular}{|c|c|c|c|c|c|}
\hline Station & Latitude $\left({ }^{\circ}\right)$ & Longitude $\left(^{\circ}\right)$ & Elevation (m) & $\begin{array}{l}\text { Measurement } \\
\text { Type }\end{array}$ & $\begin{array}{l}\text { Relationship to } \\
\text { Bend, Oregon } \\
\text { (km, direction) }\end{array}$ \\
\hline $\begin{array}{l}\text { Sisters Ranger } \\
\text { Station }\end{array}$ & 44.2925 & -121.5552 & 975 & WX & 32 km, NNW \\
\hline $\begin{array}{l}\text { Sisters Ranger } \\
\text { Station }\end{array}$ & 44.2925 & -121.5552 & 975 & Nephelometer & 32 km, NNW \\
\hline $\begin{array}{l}\text { Bridges Boys } \\
\text { Academy }\end{array}$ & 44.2274 & -121.5212 & 1079 & WX & $25 \mathrm{~km}, \mathrm{NW}$ \\
\hline Cascade Academy & 44.1327 & -121.3323 & 988 & WX & $8 \mathrm{~km}, \mathrm{NNW}$ \\
\hline Tumalo Ridge & 44.0494 & -121.4003 & 1220 & RAWS & $7 \mathrm{~km}, \mathrm{WSW}$ \\
\hline Bend Pump Station & 44.0639 & -121.3126 & 1101 & Nephelometer & In Bend \\
\hline Miller Elementary & 44.0543 & -121.3692 & 1167 & WX & $5 \mathrm{~km}, \mathrm{~W}$ \\
\hline $\begin{array}{l}\text { Cascade Middle } \\
\text { School }\end{array}$ & 44.0370 & -121.3397 & 1145 & $\mathrm{PM}_{2.5}$ & $4 \mathrm{~km}, \mathrm{SW}$ \\
\hline Lava Butte & 43.93 & -121.33 & 1344 & RAWS & 15 km, S \\
\hline Sunriver & 43.9033 & -121.4329 & 1269 & $\mathrm{PM}_{2.5}$ & $20 \mathrm{~km}, \mathrm{SSW}$ \\
\hline Round Mountain & 43.6739 & -121.7167 & 1798 & RAWS & 47 km SW \\
\hline
\end{tabular}

\subsection{Seasonal and Diurnal Wind Analysis}

In addition to determining the frequency of days in prescription, we also generated seasonal wind roses, both for day and night, to better understand wind patterns in the study area (Appendix A). We 
followed the methodology used by the WRCC to define "day" and "night" such that time windows for "daytime" winds included the interval from 11:00 am-6:00 pm PST and nighttime windows included the interval from 01:00 am-07:00 am PST. These time periods capture the general wind patterns during the day and night and attempt to reduce the inclusion of transitions associated with sunrise and sunset. Additionally, the times generally cover daytime and nighttime hours throughout the year and minimize the difference between winter and summer.

Seasons were defined by meteorological seasons with the 12 calendar months grouped into four three-month periods. Winter included the months of December, January, and February; spring included March, April, and May; summer included June, July, and August; and fall included September, October, and November. Although the DNF prescribed fire season occurs in autumn and spring, some prescribed fires took place in early June, which would be categorized in this manner as summer. This grouping aligned calendar dates more closely with temperatures during that period and allowed easier comparison of weather patterns across seasons.

We used wind data from the Tumalo Ridge RAWS (the station closest to Bend) to estimate the frequency that daytime and nighttime winds were from a direction that would carry smoke away from Bend. We assessed how often northwesterly through northeasterly winds occurred during the day (to transport smoke away from Bend) and how often southeasterly to southwesterly winds occurred during the nighttime (to determine if nighttime drainage flows are responsible for the smoke intrusions). Days and nights when both north and south winds occurred were excluded from the analysis.

\subsection{Smoldering Fuel Consumption Measurements}

Ottmar et al. [28] worked with the DNF to assess post-fire fuel consumption measurements of stumps, logs, and basal accumulations (litter and duff deposits at the base of standing trees) at two sites in the DNF representative of the burn units. These sites were the West Bend unit (located less than $5 \mathrm{~km}$ west-southwest (WSW) of downtown Bend) and the Glaze Meadow unit (approximately $40 \mathrm{~km}$ north-northwest (NNW) of downtown Bend). Their measurements provided estimates of fuel loadings and consumption, which are critical for smoke dispersion modeling. Due to the overnight timing of smoke dispersal, smoldering combustion of downed woody debris was believed to contribute to a smoke intrusion in spring 2014. Because this was a retrospective study, estimates of the timing and duration of smoldering combustion could not be determined.

Accurate estimates of fuel loadings and types are necessary for consumption and emissions predictions. While data on pre-fire fuel information for stumps, logs, and basal accumulations were unavailable, postburn data were collected approximately two months later to reconstruct the potential contribution of these three fuel-bed components to smoldering combustion and to smoke production [28]. Total maximum smoldering fuel component consumption was estimated at $3094 \mathrm{~kg} \cdot \mathrm{ha}^{-1}$ in West Bend and $17,553 \mathrm{~kg} \cdot \mathrm{ha}^{-1}$ in Meadow Glade, with over $50 \%$ of that consumption from smoldering stumps. West Bend had minimal smoldering of logs $\left(247 \mathrm{~kg} \cdot \mathrm{ha}^{-1}\right)$ while Meadow Glade had $6882 \mathrm{~kg} \cdot \mathrm{ha}^{-1}$ of smoldering logs. Consumption of basal accumulation was similar at $695 \mathrm{~kg} \cdot \mathrm{ha}^{-1}$ and $852 \mathrm{~kg} \cdot \mathrm{ha}^{-1}$ at West Bend and Meadow Glade, respectively. While the Fuel Characterization Classification System (FCCS) fuel models were used for emissions estimates, information about the smoldering combustion components was used in the smoke modeling to improve predicted $\mathrm{PM}_{2.5}$ concentrations from the intrusions analyzed in this work. However, our main focus was comparing the directionality and timing of intrusion events.

\subsection{Weather and $P M_{2.5}$ Measurement Stations}

WatchDog Weather Stations (Spectrum Technologies, Inc., Aurora, IL, USA) were deployed at six sites in 2014 and four sites in 2015 (Figure 1, Table 2) to supplement permanent stations. The portable weather stations were placed at 1.5 to $2 \mathrm{~m}$ above ground level and collected temperature, precipitation, relative humidity (RH), wind speed, wind direction, wind gust speed, wind gust direction, and dew point at 10- or 15-min intervals; however, only wind speed and wind directions were analyzed in this 
study. WatchDog 2000 Series Weather Stations measure wind speeds of 0 and between 0.3 to $89.4 \mathrm{~m} \cdot \mathrm{s}^{-1}$ with an accuracy of $\pm 0.8 \mathrm{~m} \cdot \mathrm{s}^{-1}$. Wind directions are measured in $1^{\circ}$ increments with an accuracy of $\pm 3^{\circ}$. The wind vanes were calibrated during field-deployment to establish accurate wind direction readings. Data were examined for values outside of expected ranges prior to analysis.

E-samplers (Met One Instruments, Inc., Grants Pass, OR, USA) were deployed at five sites in 2014 and three sites in 2015. These monitors were placed at 1.5 to $2 \mathrm{~m}$ above ground level and collected $\mathrm{PM}_{2.5}$ concentration data via light scattering in addition to temperature, $\mathrm{RH}$, wind speed, and wind direction. The E-sampler calculates $\mathrm{PM}_{2.5}$ concentration by applying a calibration to the measured light scattering. Four of the E-samplers recorded 1-h averages and one recorded 10-min averages in 2014. The three sensors deployed in 2015 used 15-min averages. E-samplers provide auto-ranging to measure concentrations from 1 to $65,530 \mu \mathrm{g} \cdot \mathrm{m}^{-3}$ with a sensitivity of $0.001 \mathrm{mg} \cdot \mathrm{m}^{-3}$, an accuracy of $8 \%$ for NIOSH 0600 , and precision to $0.003 \mathrm{mg} \cdot \mathrm{m}^{-3}$ or $2 \%$ reading. They use a comprehensive set of error and alarm codes to identify any problems with the unit (including critical parameters which must be working correctly for machine operation). The units used in this study were deployed intermittently for short field campaigns and periodically returned to Met One Instruments, Inc. for cleaning and calibration as needed for this type of usage. When deployed for this project, they were calibrated for pressure, temperature, and flow rate. The internal $\mathrm{RH}$ was set to $50 \%$ to reduce effects of water bound in aerosol inflating $\mathrm{PM}_{2.5}$ estimates. Filter sampling was not used.

The state of Oregon's Department of Environmental Quality (DEQ) operates two permanent nephelometers in the DNF: one at the Sisters Ranger District Office in Sisters, and the other at the Bend Pump Station. Both permanent air-quality monitors are located in urban areas (near traffic and, for the Bend location, near the Deschutes River) and are designed to capture air samples representative of the environment in those population centers. Both monitors are M903 nephelometers (Radiance Research, Seattle, WA, USA), which measure sample volumes of $0.44 \mathrm{~m}^{3}$ using a $530-\mathrm{nm}$ wavelength. These instruments also measure light scattering due to particulate matter in the atmosphere. Their range is 0 to 1 per $\mathrm{km}$ with a lower detection less than 0.001 per $\mathrm{km}$ at a 30 -s average. For these monitors, DEQ establishes a calibration curve by relating observations to Rupprecht and Patashnick P2025 PRM filter samplers and converts measurements to $\mathrm{PM}_{2.5}$ concentrations based off a linear regression model. This process is done at the Bend Pump Station every year using the most recent three years of data. Clean air zero and span calibrations are preformed every three months.

It is important to recognize that the method of observing particulate matter via light scattering is subject to uncertainty as mass scattering efficiency may be affected by chemical composition of biomass, the fraction of light absorbing black and brown carbon, and size distribution of particles [29-31]. Particles are made up of different constituents and come in many shapes and sizes. Thus, they can have different mass scattering efficiencies due to differences in both chemistry and microphysical properties [32,33]. Additionally, particles may be affected by combustion processes [34], as well as the effect of atmospheric aging (e.g., photobleaching) [30].

\subsection{Smoke Dispersion Modeling}

The BlueSky smoke modeling framework [35] was used to simulate the near-surface $\mathrm{PM}_{2.5}$ concentrations that caused the smoke intrusions. BlueSky links datasets and models of fire location and growth, fuel loadings and consumption, emissions from consumed fuels, plume rise, and smoke dispersion. The dispersion model requires meteorological model output to predict movement and concentration of smoke. While BlueSky simulation outputs provide $\mathrm{PM}_{2.5}$ concentration fields, other trace gases are calculated in the background but not simulated all the way through to a concentration field. Also, we simulated only primary $\mathrm{PM}_{2.5}$ emissions from the fires and did not take into account secondary formation or other potential sources. We used the actual fire location and size for each of the prescribed fires. This information was obtained from the intrusion reports, prepared by the DNF District Office that was responsible for the burns, and contained the dates, times, locations, sizes, and fuel loadings (Table 3). 
Table 3. Fires responsible for smoke intrusions into Bend, Oregon for fall 2014 and spring 2015. Vegetation types derived from the Fuel Characterization Classification System (FCCS) were used for BlueSky runs. PDT = Pacific Daylight Time.

\begin{tabular}{|c|c|c|c|c|c|c|c|}
\hline Burn Date & $\begin{array}{l}\text { Latitude } \\
\quad\left({ }^{\circ}\right)\end{array}$ & $\begin{array}{l}\text { Longitude } \\
\left({ }^{\circ}\right)\end{array}$ & $\begin{array}{l}\text { Elevation } \\
\text { (m) }\end{array}$ & Size (ha) & $\begin{array}{l}\text { Pre-fire Fuel } \\
\text { Loading } \\
\left(\mathrm{kg} \cdot \mathrm{ha}^{-1}\right)\end{array}$ & $\begin{array}{l}\text { Vegetation } \\
\text { Type }\end{array}$ & $\begin{array}{l}\text { Ignition Start } \\
\text { (PDT) }\end{array}$ \\
\hline 4 October 2014 & 43.7250 & -121.6323 & 1301 & 18.2 & 101,482 & $\begin{array}{l}\text { Lodgepole pine } \\
\text { Pacific }\end{array}$ & 1:57 PM \\
\hline 4 October 2014 & 43.6960 & -121.6529 & 1305 & 19.0 & 44,498 & $\begin{array}{l}\text { Ponderosa pine; } \\
\text { Douglas fir } \\
\text { Pacific }\end{array}$ & 11:14 AM \\
\hline 4 October 2014 & 43.7105 & -121.6329 & 1302 & 20.3 & 44,498 & $\begin{array}{l}\text { Ponderosa pine; } \\
\text { Douglas fir }\end{array}$ & 11:30 AM \\
\hline 4 May $2015^{*}$ & 43.6571 & -121.8360 & 1525 & 46.2 & 182,990 & Lodgepole pine & 9:30 AM \\
\hline 5 May 2015 & 43.9611 & -121.3339 & 1266 & 4.9 & 30,734 & $\begin{array}{l}\text { Ponderosa pine } \\
\text { savanna }\end{array}$ & 10:45 AM \\
\hline 28 May 2015 & 44.0242 & -121.3839 & 1312 & 27.9 & 21,005 & $\begin{array}{l}\text { Western juniper; } \\
\text { sagebrush } \\
\text { savanna }\end{array}$ & $11: 25 \mathrm{AM}$ \\
\hline 5 June 2015 & 44.0423 & -121.3975 & 1220 & 49.4 & 21,005 & $\begin{array}{l}\text { Western juniper; } \\
\text { sagebrush } \\
\text { savanna }\end{array}$ & 11:00 AM \\
\hline 6 June 2015 & 44.0136 & -121.3975 & 1234 & 55.9 & 21,005 & $\begin{array}{l}\text { Western juniper; } \\
\text { sagebrush } \\
\text { savanna }\end{array}$ & 10:00 AM \\
\hline
\end{tabular}

* 4 May 2015 fuels were customized from FCCS \#22 by increasing duff depth from 5.1 to $12.7 \mathrm{~cm}$.

Six smoke intrusions impacted the city of Bend over the fall of 2014 and spring of 2015 prescribed fire seasons (Table 4). Fuel loadings were obtained from the Fuel Characterization Classification System (FCCS) mapped at a 1-km resolution [36]. We used FCCS fuel models since it is not uncommon for fuel loadings to vary by an order of magnitude for a site [37]. Additionally, our main interest was to compare the directionality and timing of predicted and observed smoke dispersion and did not include a comprehensive assessment of concentrations. Therefore, site-specific fuel information was not incorporated into the BlueSky framework although that capability does exist. Total pre-fire fuel loadings used in the model runs are given in Table 3.

Table 4. Summary of smoke intrusion episodes into Bend, Oregon for fall of 2014 and spring of 2015.

\begin{tabular}{|c|c|c|c|c|c|}
\hline Burn Date & Intrusion Start (PDT) & $\begin{array}{c}\text { Intrusion } \\
\text { Duration (h) }\end{array}$ & $\begin{array}{l}\text { Maximum 1-h } \\
\mathrm{PM}_{2.5}\left(\mu \mathrm{g} \cdot \mathrm{m}^{-3}\right)\end{array}$ & $\begin{array}{l}\text { Maximum 24-h } \\
\mathrm{PM}_{2.5}\left(\mu \mathrm{g} \cdot \mathrm{m}^{-3}\right)\end{array}$ & $\begin{array}{l}\text { Relationship to } \\
\text { Bend, Oregon (km, } \\
\text { direction) }\end{array}$ \\
\hline $\begin{array}{l}4 \text { October } 2014 \\
4 \text { October } 2014 \\
4 \text { October } 2014\end{array}$ & $\begin{array}{c}\text { 3:00 AM. } \\
5 \text { October } 2014\end{array}$ & 10 & 96 & 26 & $\begin{array}{l}45 \mathrm{~km}, \text { SSW } \\
49 \mathrm{~km}, \mathrm{SSW} \\
47 \mathrm{~km}, \mathrm{SSW}\end{array}$ \\
\hline 4 May 2015 & 1:00 PM. 4 May 2015 & 2 & 13 & 5 & $60 \mathrm{~km}, \mathrm{WSW}$ \\
\hline 5 May 2015 & 7:00 AM. 6 May 2015 & 1 & 11 & 2.3 & 11 km, SSW \\
\hline 28 May 2015 & 1:00 AM. 29 May 2015 & 7 & 181 & 27 & 7 km, SW \\
\hline 5 June 2015 & 10:00 PM. 5 June 2015 & 12 & 130 & 25 & $7 \mathrm{~km}, \mathrm{WSW}$ \\
\hline 6 June 2015 & 12:00 AM. 7 June 2015 & 10 & 245 & 38 & 9 km, SW \\
\hline
\end{tabular}

A three-dimensional wind field from the Weather Research and Forecasting (WRF) model [38,39] was used to drive BlueSky, and the Hybrid Single-Particle Langrangian Integrated Trajectory (HYSPLIT) model was used for the dispersion simulations [40,41] (Table 5). The spatial and temporal resolutions of the BlueSky runs were determined by the meteorological model. In this case, we used the hourly 4-km-resolution WRF model provided by the University of Washington Department of Atmospheric Sciences [42]. Additionally, we had available a 1-km-resolution meteorological model from the National Centers for Environmental Prediction (NCEP) North American Mesoscale Forecast System (NAM) [43] for the 4-5 October 2014 smoke intrusion period. Smoke modeling with these data provide hourly predictions of near-surface $\mathrm{PM}_{2.5}$ concentrations. The suites of portable meteorological and $\mathrm{PM}_{2.5}$ monitors were not deployed for the October 2014 episode, but smoke dispersion modeling was possible 
and the modeled meteorological wind fields were compared with those obtained from RAWS stations. Modeled $\mathrm{PM}_{2.5}$ values were compared with $\mathrm{PM}_{2.5}$ measurements at the Bend Pump Station.

Table 5. The BlueSky Smoke Modeling Framework configuration used for modeling smoke production and transport from the prescribed fires.

\begin{tabular}{ll}
\hline BlueSky Framework & Version 3.1.5 \\
Meteorological Model & $\begin{array}{l}\text { Weather Research and Forecasting (WRF) 3.1.1 (4-km, 1-h } \\
\text { intervals); North American Mesoscale Forecast System (NAM) } \\
\text { (1-km, 1-h intervals) }\end{array}$ \\
$\begin{array}{l}\text { Fuel Loadings } \\
\text { Consumption Model }\end{array}$ & $\begin{array}{l}\text { Consume Version 3.0 } \\
\text { Emissions Model }\end{array}$ \\
Dispersion Model & Fire Emission Production Simulator (FEPS) Version 1.0 \\
& $\begin{array}{l}\text { Hybrid Single-Particle Langrangian Integrated Trajectory } \\
\text { (HYSPLIT) Version 4.9 }\end{array}$ \\
\hline
\end{tabular}

\section{Results}

\subsection{Acceptable Burn Days}

From 2006-2015, Tumalo Ridge had 259 burn days, Lava Butte had 264 burn days, and Round Mountain had 280 burn days within acceptable meteorological parameters for prescribed fire (Figure 2). Therefore, an average of 26-28 burn days occurred each year including 1-6 prescription days per month in the spring and 2-4 prescription days per month in the fall. While 2-7 days per month were in prescription during the summer, they are not generally considered suitable for prescribed fires due to the risk of wildfire. Considerable data gaps existed in the RAWS data during mostly the winter months; thus, those data were probably biased low during these times. However, fuel moistures may be too high in the winter to adequately carry fire, and ignition may be impossible if snowfall covers surface fuels. Greater confidence was placed in the spring, summer, and fall months of data (highlighted by boxes around those months in Figure 2). With regard to the seasonality and spatial variation of the region's meteorological patterns, conditions amenable to prescribed fire occurred early in the spring at Tumalo Ridge and later in the spring at Lava Butte and Round Mountain. While all three stations showed acceptable conditions in the fall, this appeared to be the only time that Round Mountain had a substantial number of days within prescription outside of the late spring and summer.

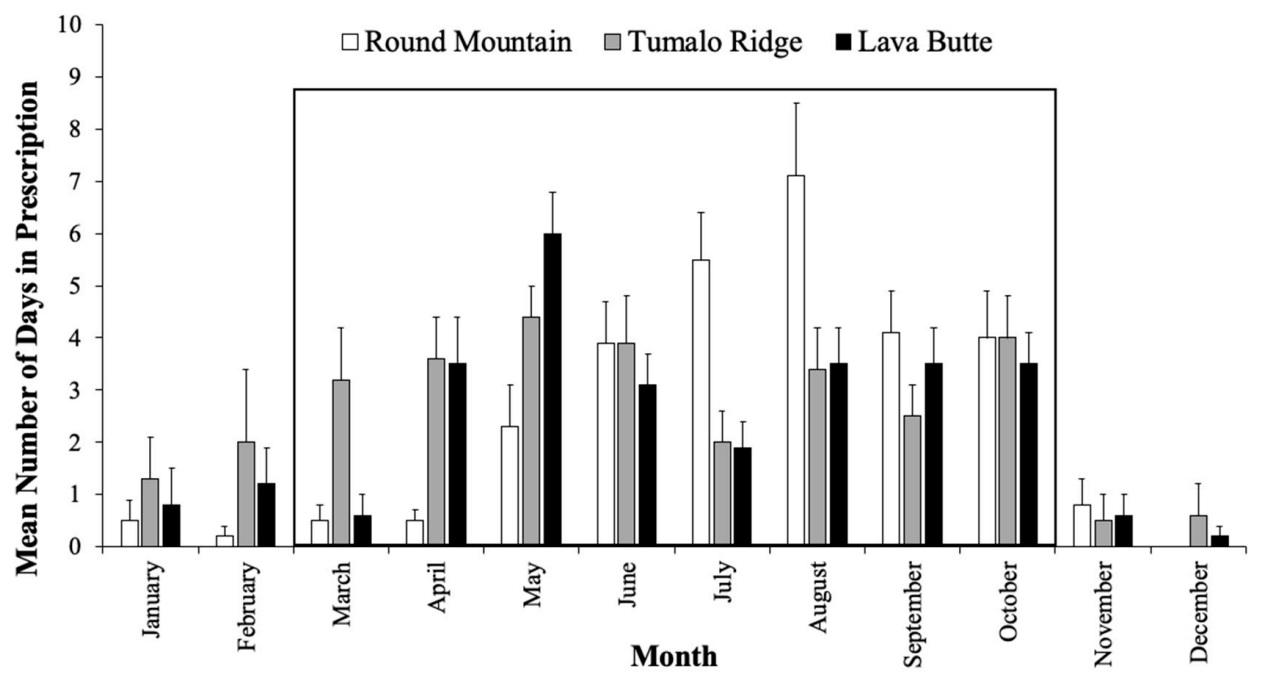

Figure 2. Mean number of days with weather conditions within prescription, by month, 2006-2015 for Lava Butte, Round Mountain, and Tumalo Ridge RAWS locations. Error bars represent the standard error of the mean for each month over the 10-year period. The box surrounding March-October encompasses months when complete data were available. 


\subsection{Seasonal and Diurnal Wind Analysis}

The most suitable wind conditions in this region occurred when north winds occurred during the day and south winds did not occur at night. Nighttime southerly winds occurred $69-80 \%$ of the time, making acceptable wind conditions a somewhat rare occurrence (Table 6). On days that met meteorological conditions for prescribed fire, ideal wind conditions were more frequent in the spring (13\%) than in the fall (5\%). The Tumalo Ridge RAWS location showed strong S-WSW flows at night for all seasons while the Lava Butte nighttime wind was SSW-WSW (Appendix A). During the day, Lava Butte also had a similar pattern of SW flows with some northerly flows as well. The Round Mountain RAWS location, which is situated at a higher elevation $(1798 \mathrm{~m})$ and further $(47 \mathrm{~km})$ from Bend, was different in that it had a NW pattern, with some flows from all directions as well. Seasonal analysis shows that these wind conditions occurred $77 \%$ of the time annually.

Table 6. Percentage of days when nighttime south winds and daytime north winds occurred at the Tumalo Ridge RAWS from 2006-2015. Ideal wind conditions are when north winds occur during the day and south winds do not occur at night. "Annual" analysis takes into account all days of the year. "Annual burn" analysis takes into account only days that meet the prescribed fire prescription window parameters; this also applies for spring and fall. Days and nights when both north and south winds occurred were excluded from the analysis.

\begin{tabular}{lccccc}
\hline Time of Year & $\begin{array}{c}\text { Day North } \\
\text { Wind Yes }\end{array}$ & $\begin{array}{c}\text { Day North } \\
\text { Wind No }\end{array}$ & $\begin{array}{c}\text { Night South } \\
\text { Wind Yes }\end{array}$ & $\begin{array}{c}\text { Night South } \\
\text { Wind No }\end{array}$ & $\begin{array}{c}\text { “Ideal” Wind } \\
\text { Conditions }\end{array}$ \\
\hline Annual & $36 \%$ & $45 \%$ & $77 \%$ & $15 \%$ & $7 \%$ \\
Annual burn & $46 \%$ & $38 \%$ & $75 \%$ & $17 \%$ & $8 \%$ \\
Spring & $45 \%$ & $36 \%$ & $77 \%$ & $12 \%$ & $7 \%$ \\
Spring burn & $50 \%$ & $36 \%$ & $69 \%$ & $21 \%$ & $13 \%$ \\
Fall & $35 \%$ & $44 \%$ & $77 \%$ & $17 \%$ & $9 \%$ \\
Fall burn & $46 \%$ & $38 \%$ & $80 \%$ & $14 \%$ & $5 \%$ \\
\hline
\end{tabular}

\subsection{Smoke Intrusions}

Smoke from prescribed fires intruded into Bend on one occasion in October 2014 and five occasions in May through June 2015 (Table 4). The 4 May 2015 intrusion was the shortest duration and lowest concentration and occurred during the daytime hours. The other five intrusions occurred in the evening, overnight, and early morning hours, with $1-\mathrm{h} \mathrm{PM}_{2.5}$ concentrations up to $245 \mu \mathrm{g} \cdot \mathrm{m}^{-3}$. Here, we discuss the measured meteorological conditions contributing to these intrusions, a graphical and statistical analysis of the modeled wind field from the 4-km WRF meteorological prediction system for all six intrusions, and the modeled 1-km-resolution wind field from NAM for the October 2014 intrusion.

Three prescribed fires were ignited on 4 October 2014 approximately $44 \mathrm{~km} \mathrm{SSW}$ of Bend (Figure 1). Each burn unit was between 18 and 20 ha. Ignition occurred between 11:00 a.m. Pacific Daylight Time (PDT) and 2:00 p.m. PDT, and smoke was initially carried away from Bend. Overnight, however, conditions changed, and smoke was transported into the city. Elevated $\mathrm{PM}_{2.5}$ values registered an intrusion starting at 2:00 a.m. PDT on 5 October, dissipating by 12:00 p.m. PDT. A maximum 1-h PM PM $_{2.5}$ concentration of $96 \mu \mathrm{g} \cdot \mathrm{m}^{-3}$ was recorded at the Bend Pump Station at 3:00 a.m. PDT, with a second peak of $94 \mu \mathrm{g} \cdot \mathrm{m}^{-3}$ at 9:00 a.m. PDT (Figure 3). While using the 1-km-resolution NAM wind field from the NCEP captured the timing of the intrusion relatively well (within $1 \mathrm{~h}$ ), the model predicted substantially lower concentration of $\mathrm{PM}_{2.5}$. Note, however, that the measured and modeled $\mathrm{PM}_{2.5}$ was not the same here; our model only simulated primary $\mathrm{PM}_{2.5}$ and did not consider secondary particulate matter or other sources. The 4-km-resolution WRF meteorological prediction resulted in concentration estimates of $0 \mu \mathrm{g} \cdot \mathrm{m}^{-3}$ in Bend during the intrusion period. 


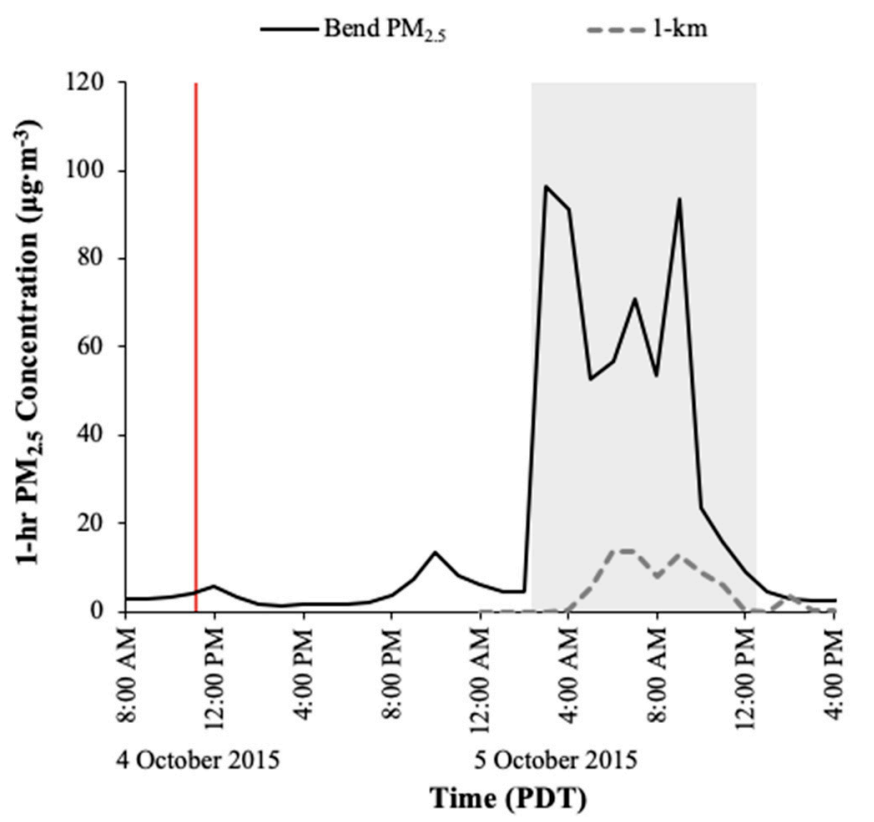

Figure 3. Measured $\mathrm{PM}_{2.5}$ concentrations and concentrations modeled using the 1-km-resolution North American Mesoscale Forecast System (NAM) model on 4-5 October2014, at the Bend Pump Station. The red line indicates time of ignition, and the shaded area represents the time of the intrusion.

With the 1-km-resolution NAM meteorological model domain (36-h forecast) from the NCEP available in addition to the 4-km WRF meteorological domain, we also did a comparison of winds and smoke dispersion with the two resolutions at the three available RAWS locations (Tumalo Ridge, Lava Butte, and Round Mountain). Wind direction mean errors for both 1-km (left side of Figure 4) and 4- $\mathrm{km}$ (right side of Figure 4) resolutions, day and night, are shown for the 36-h period. For the 1-km-resolution domain, daytime mean errors ranged from $45^{\circ}$ to $80^{\circ}$, while nighttime mean errors ranged from $20^{\circ}$ to $80^{\circ}$. For the 4- $\mathrm{km}$-resolution domain, daytime mean errors ranged from $38^{\circ}$ to $60^{\circ}$ and nighttime mean errors ranged from less than $10^{\circ}$ to greater than $80^{\circ}$.

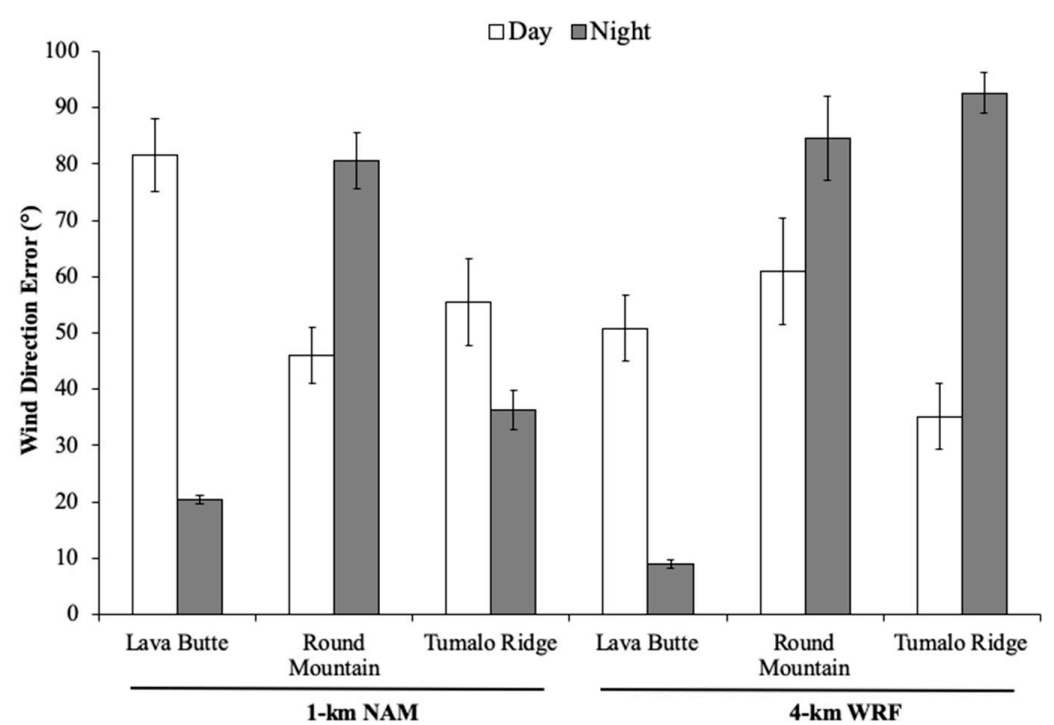

Figure 4. 4-6 October2014. Daytime and nighttime mean wind direction error of modeled minus measured wind data at the three RAWS locations. The 1-km-resolution North American Mesoscale Forecast System (NAM) model is on the left side, and the 4-km-resolution Weather Research and Forecasting (WRF) model is on the right side. Error bars represent the standard error of the mean. 
The BlueSky smoke model simulations using both the 1-km-resolution NAM and the 4-km-resolution WRF data showed that smoke transported down the drainage from the SSW into Bend (Figure 5a,b, respectively). The plumes arrived at approximately 3:00 a.m. PDT, in agreement with the measured data. Predicted concentrations were lower than measured (approximately 10-15 $\mu \mathrm{g} \cdot \mathrm{m}^{-3}$ for the 1-km-resolution NAM output and less than $1 \mu \mathrm{g} \cdot \mathrm{m}^{-3}$ (in effect, zero) for the 4-km-resolution WRF output (Figure 3). This was probably due to BlueSky not fully capturing the smoldering of basal accumulations and large woody debris. While the plume initially traveled to the northeast, winds shifted to the SW before dispersion and recirculation broke it up. At 7:00 a.m. PDT, approximately $20 \mathrm{~h}$ after the ignition of the prescribed fire, the simulation using the 1-km-resolution NAM model showed a well-defined plume transported along the drainage. The lower-resolution 4-km-resolution WRF model simulation carried some smoke toward Bend overnight; however, for the most part, the model results showed the plume east of the city.

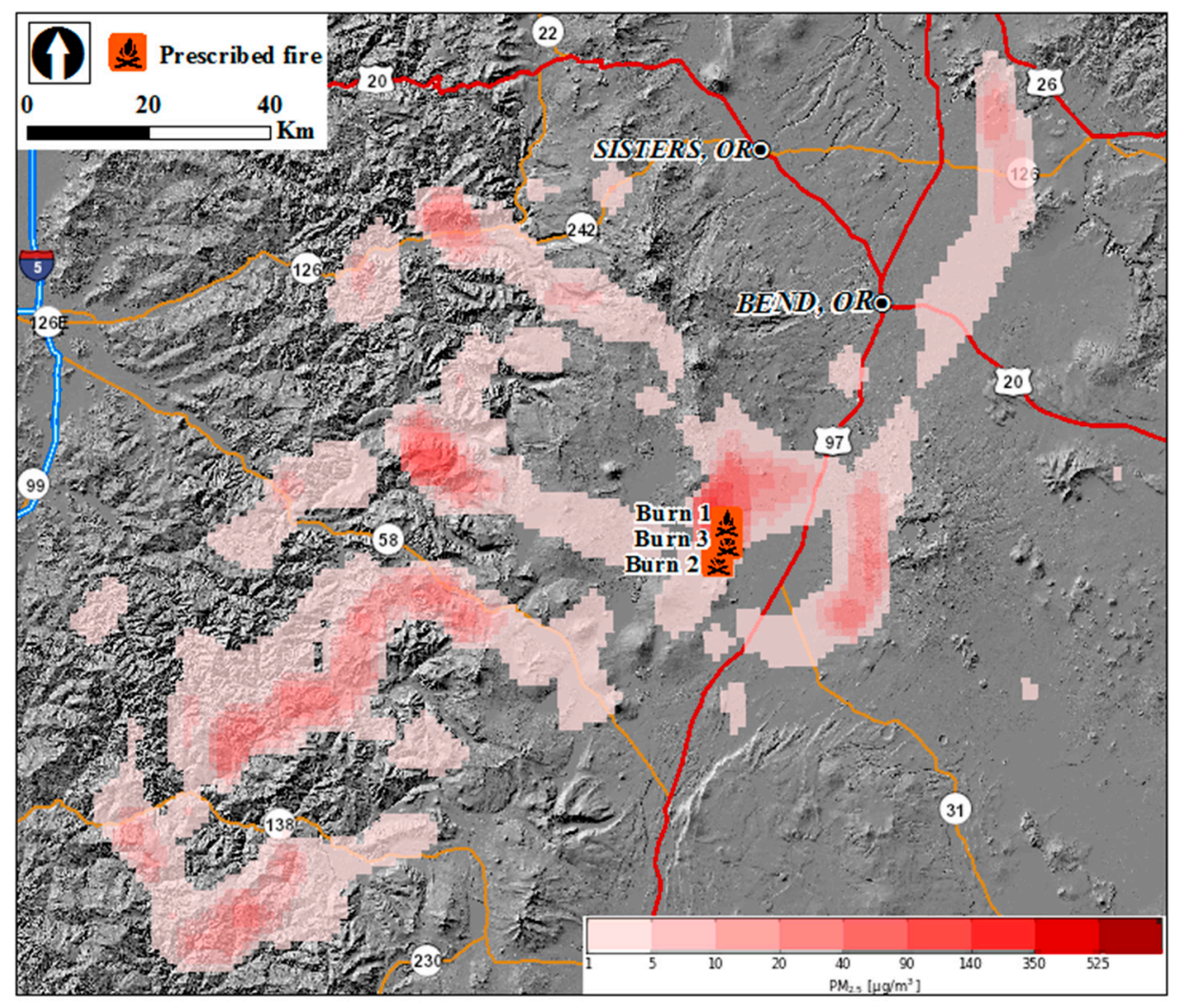

(a)

Figure 5. Cont. 


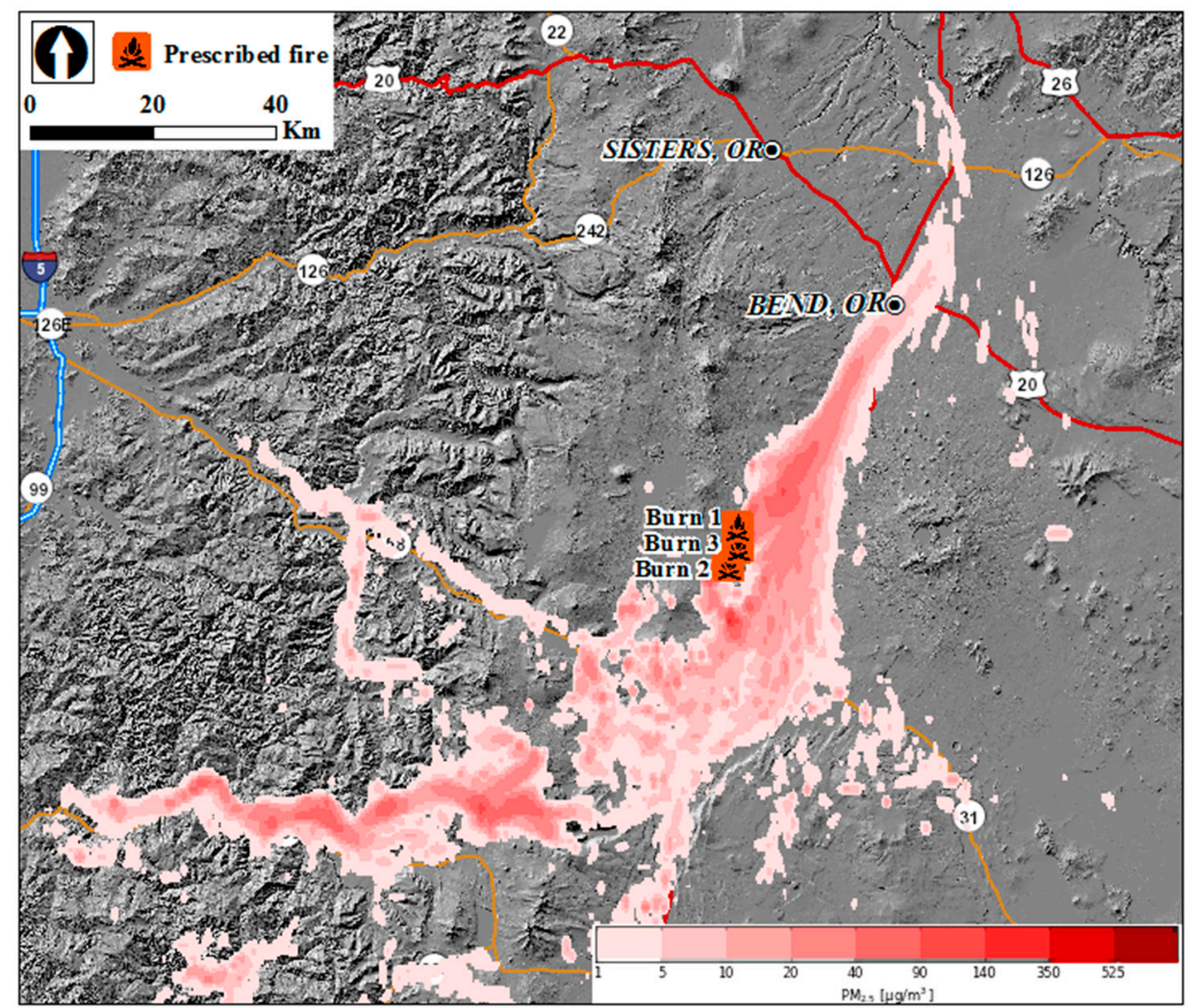

(b)

Figure 5. (a) BlueSky output using 4-km-resolution Weather Research and Forecasting (WRF) model, valid time 7:00 a.m. Pacific Daylight Time (PDT), 5 October 2014; (b) BlueSky output using 1-km-resolution North American Mesoscale Forecast System (NAM) model, valid time 7:00 a.m. PDT, 5 October 2014.

A 46-ha prescribed fire was ignited at 9:30 a.m. PDT on 4 May 2015, approximately $60 \mathrm{~km}$ southwest of Bend (Figure 1). Smoke was transported into Bend within 3.5 hours of ignition with a maximum concentration of $13 \mu \mathrm{g} \cdot \mathrm{m}^{-3}$ recorded at the Bend Pump Station nephelometer. Concentrations were elevated for approximately two hours. Before ignition, the Tumalo Ridge RAWS measured winds from the north; however, by the time of ignition, the winds were from the south. Winds were steady from the WSW during the intrusion period, indicating that smoke could be transported into Bend. Conversely, the Round Mountain RAWS location, which was the closest wind monitor to the burn, had WNW winds at the time of ignition and throughout the afternoon, suggesting the wind should have carried the smoke away from the city. Other weather stations located along the highway (Hwy) 97 corridor between Bend and the burn measured predominantly southerly winds at the time of ignition, switching to the SW in the afternoon (see the first ignition time and shaded area in Figure 6). Both the modeled and the measured wind data showed abrupt shifts in direction when the wind speeds decreased below approximately $2 \mathrm{~m} \cdot \mathrm{s}^{-1}$ overnight. Additionally, the WRF model generally overpredicted the wind speeds. 


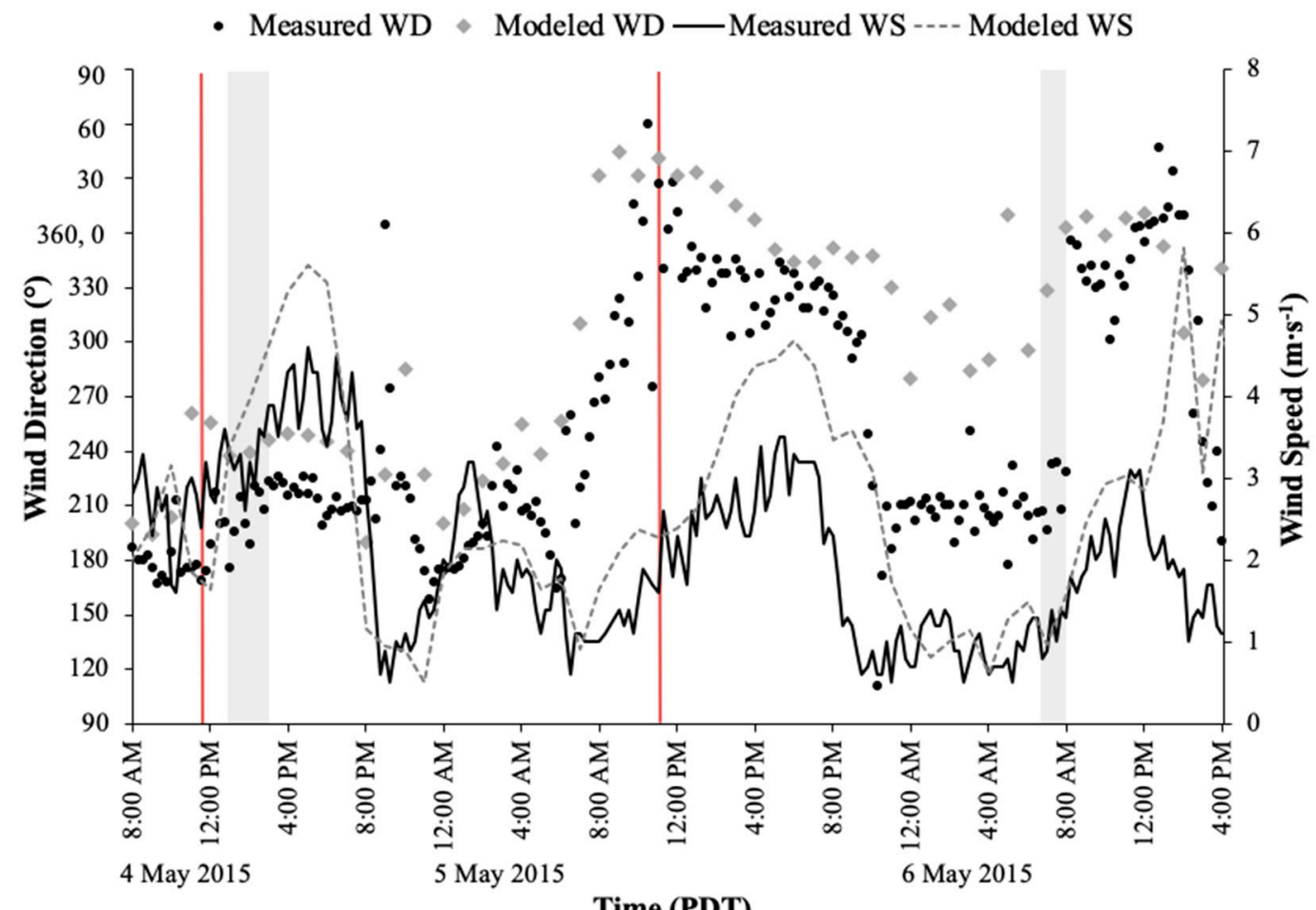

Time (PDT)

Figure 6. Measured and modeled wind direction (WD) and wind speed (WS) at Cascade Middle School for 4-6 May 2015. Modeled winds are reported from the 4-km-resolution Weather Research and Forecasting (WRF) model operated by the University of Washington. Red lines indicate burn ignition times and gray-shaded areas indicate the smoke intrusion periods into Bend, Oregon. The wind direction scale starts at $90^{\circ}$ (coming from the east) and ends at $90^{\circ}$.

BlueSky smoke modeling results simulated the timing of the transport of the smoke into Bend (Figure 7), with concentrations from the model run using the increased fuel loadings. However, the modeled BlueSky 1-h $\mathrm{PM}_{2.5}$ concentrations at the Bend Pump Station were still an order of magnitude less than the concentrations measured by the nephelometer, with concentrations of 0.05 to $0.47 \mu \mathrm{g} \cdot \mathrm{m}^{-3}$ predicted between 1:00 and 3:00 p.m. PDT compared to the observed results of 4.8 to $12.6 \mu \mathrm{g} \cdot \mathrm{m}^{-3}$. The model output shown in Figure 7 is from approximately $4 \mathrm{~h}$ after ignition, with steady winds pushing the plume centerline to the south of Bend. Only the plume fringes were predicted to impact Bend. Assessing Figure 6 (first intrusion, gray-shaded area), which shows measured and modeled wind speed and wind direction data at Cascade Middle School, modeled winds were WSW, while measured winds were SSW. Thus, a shift in the modeled winds that included a stronger southerly component would have aligned the wind field more closely to the observed direction and could have brought the plume more directly into Bend.

The five nighttime and early morning intrusions in 2015 all exhibited similar characteristics. The prescribed fires were located 6-10 km SSW of Bend. During the day northeast (NE)-NW winds transported smoke away from the city. Overnight winds decreased and turned to the SW, and $\mathrm{PM}_{2.5}$ concentrations became elevated in Bend. BlueSky 4-km-resolution simulations weakly simulated smoke transport into Bend for the 5 May intrusion around midnight, but did not bring smoke into the city during the intrusion period of 6:00 to 8:00 a.m. PDT. BlueSky simulations also failed to bring smoke into Bend for the 28 May, 5 June, and 6 June intrusions. 


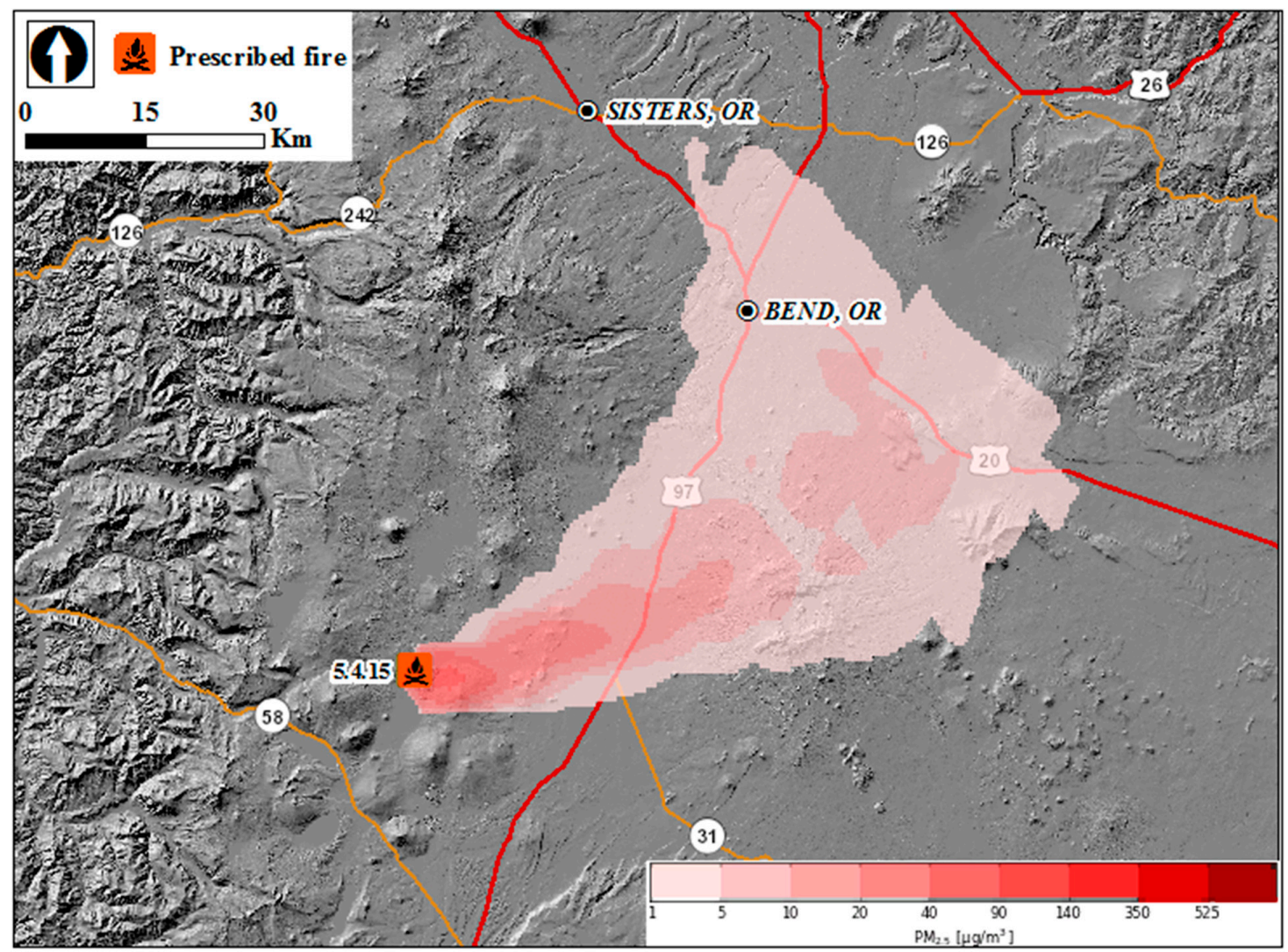

Figure 7. BlueSky output using 4-km-resolution Weather Research and Forecasting (WRF) model, valid time 2:00 p.m. PDT, 4 May 2015.

Figure 6, Figure 8, and Figure 9 illustrate the measured wind directions and wind speeds in Bend, measured at Cascade Middle School, for each of the intrusions. During the overnight intrusion periods (see the second shaded area of Figure 6 and all the shaded areas in Figures 8 and 9), the 4-km-resolution WRF modeled that winds remained from the NW, while measured winds were from the SSW. Mean wind direction errors ranged from $89-108^{\circ}$ at night at this location (Appendix B). Figure 10 shows box plots of the day and night wind direction mean error values for all the intrusion periods. In general, mean wind direction errors were greater at night than during the day. The modeled wind speeds were generally biased high (but within 1 to $3 \mathrm{~m} \cdot \mathrm{s}^{-1}$ of the observed values), and calm winds (less than $0.25 \mathrm{~m} \cdot \mathrm{s}^{-1}$ ) registered greater than $50 \%$ of the time at four out of the nine stations (Table 7), largely due to calm winds overnight (Appendix B). Again, the shift in wind direction overnight when speeds reduced to nearly $1 \mathrm{~m} \cdot \mathrm{s}^{-1}$ was evident during the intrusions on 28 May, 5 June, and 6 June 2015. While the modeled wind direction data captured this occurrence, it was not of the same magnitude. 


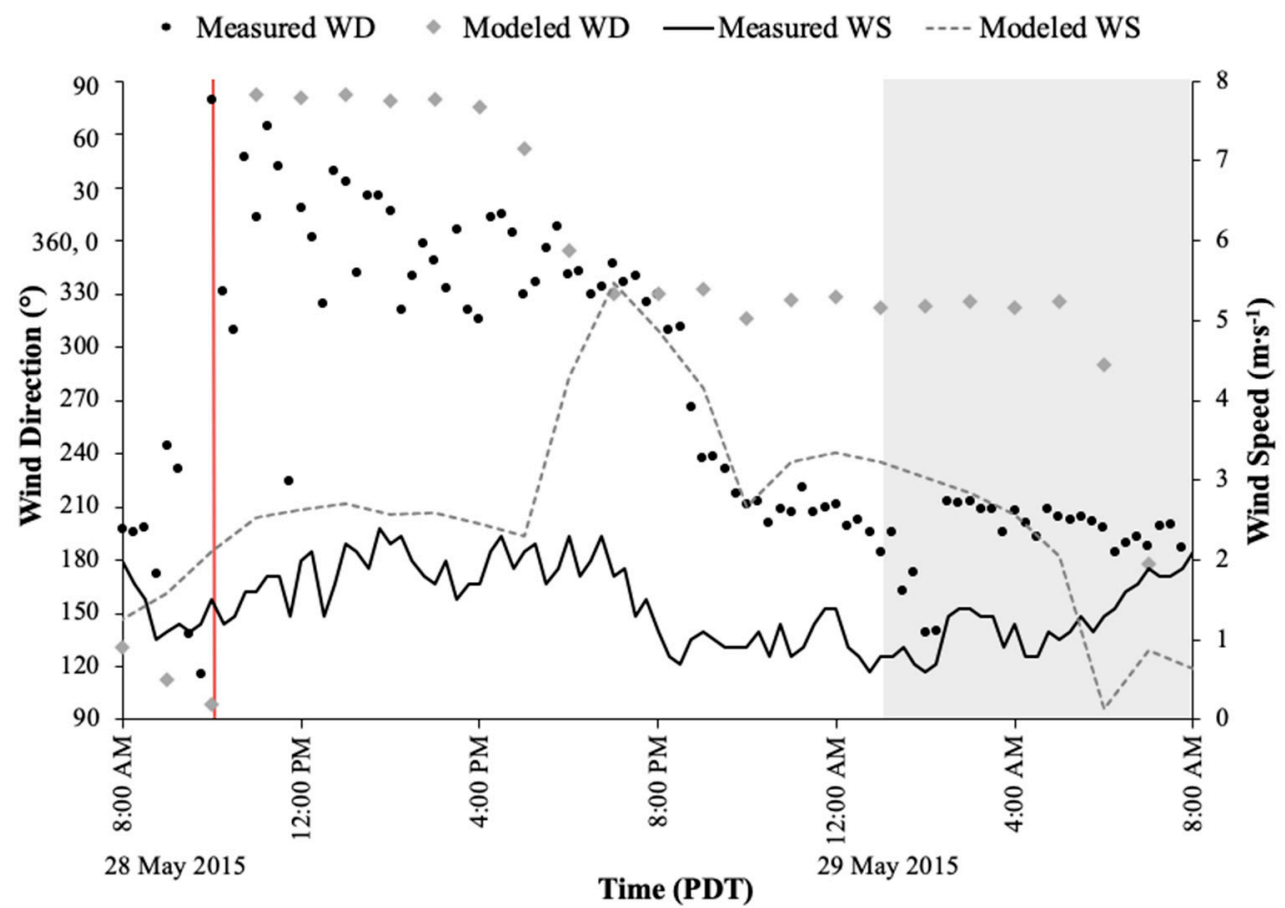

Figure 8. Measured and modeled wind direction (WD) and wind speed (WS) at Cascade Middle School for the 28 May to 29 May 2015 intrusion. Modeled winds are reported from the 4-km-resolution Weather Research and Forecasting (WRF) model operated by the University of Washington. The red line indicates burn ignition time, and the gray-shaded area indicates the smoke intrusion period into Bend. The wind direction scale starts at $90^{\circ}$ (coming from the east) and ends at $90^{\circ}$.

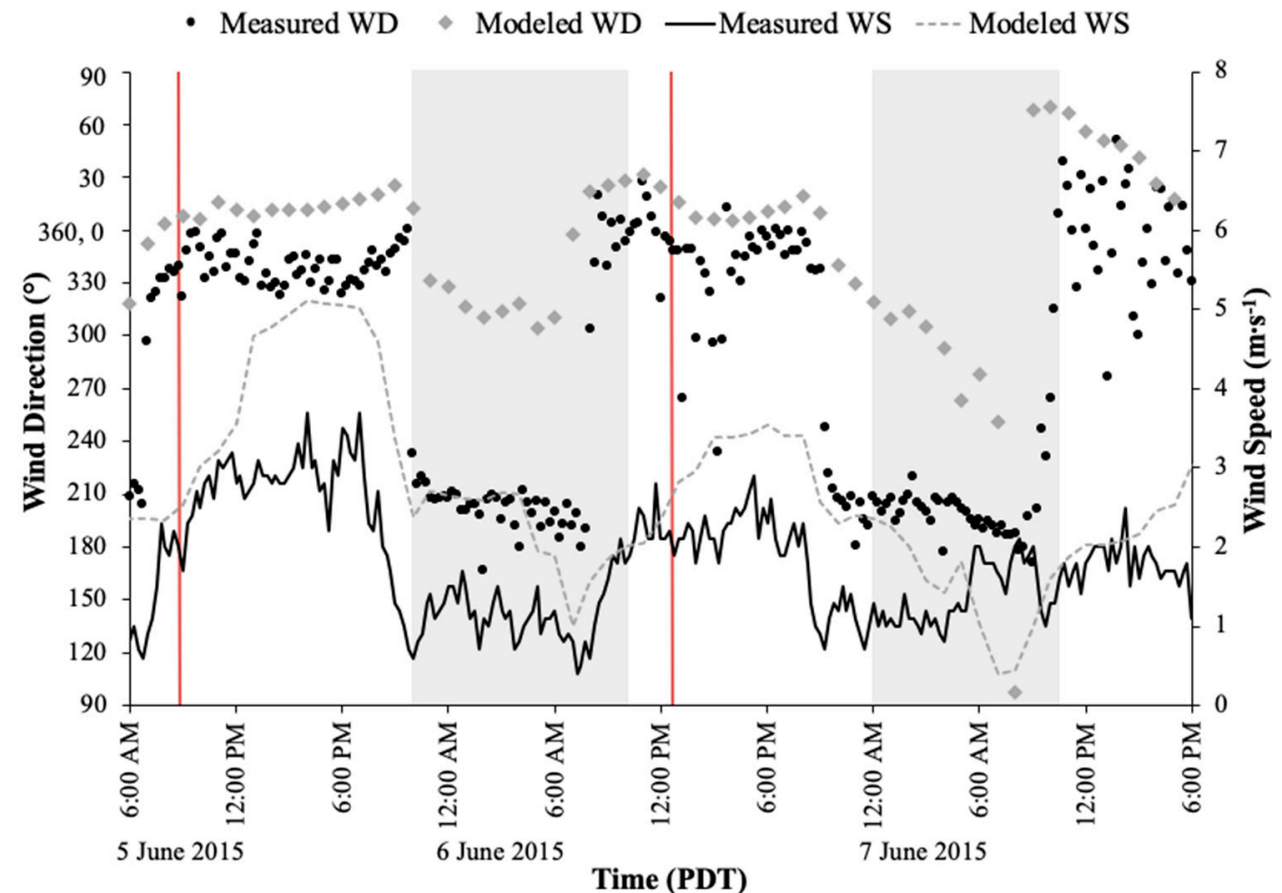

Figure 9. Measured and modeled wind direction (WD) and wind speed (WS) at Cascade Middle School for the 5-6 June 2015 smoke intrusions. Modeled winds are reported from the 4-km-resolution Weather Research and Forecasting (WRF) model operated by the University of Washington. Red lines indicate burn ignition times, and gray-shaded areas indicate the smoke intrusion periods into Bend. The wind direction scale starts at $90^{\circ}$ (coming from the east) and ends at $90^{\circ}$. 


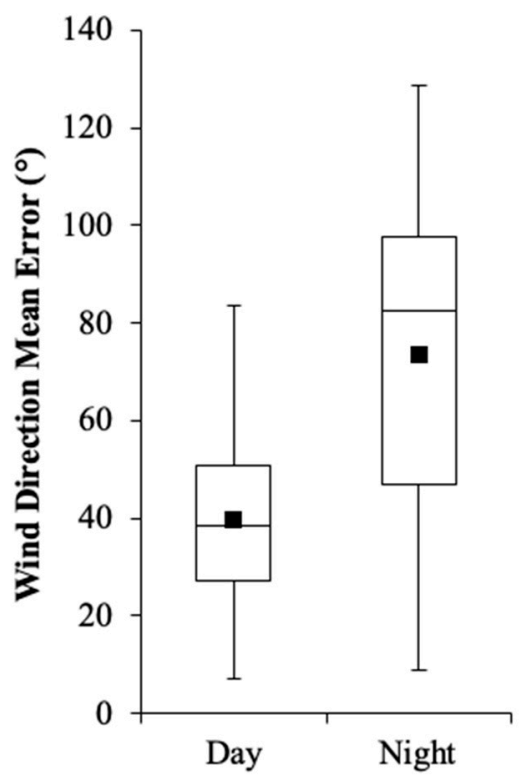

Figure 10. Box plots showing day and night medians (center line), 25th and 75th percentiles (bottom and top of the box, respectively), maximum and minimum values (whiskers), and mean (black box) wind direction errors (modeled vs. observed) for the 2015 intrusion model runs. Modeled winds are reported from the 4-km-resolution WRF data. Calm winds were considered less than $0.25 \mathrm{~m} \cdot \mathrm{s}^{-1}$.

Table 7. Wind speed (WS) mean bias, wind speed mean error, and wind direction (WD) mean error at the meteorological measurement stations for the 2015 smoke intrusion periods. Model data are from the 4-km-resolution Weather Research and Forecasting (WRF) model operated by the University of Washington. Station locations are listed north to south. Calm winds include values under $0.25 \mathrm{~m} \cdot \mathrm{s}^{-1}$.

\begin{tabular}{|c|c|c|c|c|c|c|}
\hline \multirow{2}{*}{ Station } & \multicolumn{2}{|c|}{ 4-6 May 2015} & \multicolumn{2}{|c|}{ 28-29 May 2015} & \multicolumn{2}{|c|}{ 5-7 June 2015} \\
\hline & $\begin{array}{l}\text { WS Bias/Error } \\
\left(\mathrm{m} \cdot \mathrm{s}^{-1}\right)\end{array}$ & $\begin{array}{l}\text { WD Error } \\
\left({ }^{\circ}\right)\end{array}$ & $\begin{array}{l}\text { WS Bias/Error } \\
\left(\mathbf{m} \cdot \mathbf{s}^{-1}\right)\end{array}$ & $\begin{array}{l}\text { WD Error } \\
\left({ }^{\circ}\right)\end{array}$ & $\begin{array}{l}\text { WS Bias/Error } \\
\left(\mathrm{m} \cdot \mathrm{s}^{-1}\right)\end{array}$ & $\begin{array}{l}\text { WD Error } \\
\left(^{\circ}\right)\end{array}$ \\
\hline $\begin{array}{l}\text { Sisters Ranger } \\
\text { Station }\end{array}$ & $2.9 / 3.0(50 \%$ calm $)$ & 49.3 & $1.7 / 1.7(88 \%$ calm $)$ & 43.5 & $2.5 / 2.5(79 \%$ calm $)$ & 47.3 \\
\hline $\begin{array}{c}\text { Bridges Boys } \\
\text { Academy }\end{array}$ & $1.3 / 1.5(40 \%$ calm $)$ & 43.1 & $1.1 / 1.4(63 \%$ calm $)$ & 48.0 & 1.1/1.1 (44\% calm) & 27.2 \\
\hline Cascade Academy & $2.0 / 2.0(67 \%$ calm $)$ & 43.8 & 1.3/1.3 (71\% calm) & 45.4 & $2.8 / 2.8(63 \%$ calm $)$ & 38.3 \\
\hline $\begin{array}{l}\text { Tumalo Ridge } \\
\text { RAWS }\end{array}$ & $0.6 / 1.1$ & 42.9 & $0.6 / 0.9$ & 58.6 & $0.9 / 1.1$ & 40.8 \\
\hline Miller Elementary & $1.6 / 1.8(52 \%$ calm $)$ & 33.8 & 1.8/1.8 (79\% calm) & 70.2 & 2.6/2.6 (56\% calm) & 29.7 \\
\hline $\begin{array}{l}\text { Cascade Middle } \\
\text { School }\end{array}$ & $0.4 / 0.7$ & 59.9 & $0.7 / 1.0$ & 85.4 & $0.9 / 1.1$ & 74.3 \\
\hline Lava Butte RAWS & $0.7 / 1.4(10 \%$ calm $)$ & 34.8 & $0.9 / 1.3(33 \%$ calm $)$ & 59.4 & $2.0 / 2.0(19 \%$ calm $)$ & 39.2 \\
\hline Sunriver & $-0.6 / 1.0(31 \%$ NA $)$ & 71.2 & $0.4 / 1.2$ & 94.0 & $0.9 / 1.1$ & 55.4 \\
\hline $\begin{array}{c}\text { Round Mountain } \\
\text { RAWS }\end{array}$ & $-0.2 / 1.4$ & 13.8 & $-0.7 / 1.5$ & 59.5 & $0.1 / 1.6$ & 62.6 \\
\hline
\end{tabular}

\section{Discussion}

\subsection{Acceptable Burn Days}

The RAWS data showed that there were relatively few days (1-6 prescription days per month in the spring and 2-4 prescription days per month in the fall) that met the desired conditions for prescribed fire. Although some days occurred during the summer months (2-7 prescription days per month), these occasions are not typically used for prescribed fire since they coincide with wildfire season. These results provide managers a context for deciding how much area should be included in burn units based on the desired treatment goals and potential number of days that can be expected to be available to conduct prescribed fires. Regarding the missing observations over the winter months (when RAWS locations may be shut down or inactive), our results are likely sufficient for planning purposes due to the tendency for conducting prescribed fires in the spring and autumn. The analysis 
of burn days did not account for wind direction, which may further impact the ability to conduct prescribed fires without exceeding regulatory constraints regarding air quality, even on days when fire behavior may be within limits. However, we separately assessed both seasonal and diurnal wind patterns in the area.

Our results also highlight the spatial variation in weather patterns across the study area and, thus, the importance of locating burn units and timing their treatment relative to likely weather patterns. Because different locations were within prescription at different times throughout the spring and fall, burn units could be scheduled for ignition using a timeline that considers the importance of achieving treatments in a specific location at a certain time of year.

General meteorological prescription parameters are based on fire behavior models and weather conditions used to estimate fire behavior and reduce the risk of escape, minimize the cost of control, and reduce impacts on the surrounding environment [44]. However, variations in fuels and weather may cause unpredictable fire behavior, which poses risks to fire suppression activities [45]. A fine balance needs to be achieved; fuel moistures must be low enough so the fuels will ignite and carry the fire, but not so low that the fire could get out of control. Likewise, the air temperature and relative humidity must be warm and dry enough so the fire will carry, but again not so hot and dry that the fire could burn uncontrollably, as happened in New Mexico with the Cerro Grande Fire near Los Alamos National Lab in 2000 [46]. The generally low estimate of potential days available for conducting prescribed fire in this analysis highlights the difficulty of achieving this balance.

\subsection{Seasonal and Diurnal Wind Analysis}

Wind speed and direction are critical for determining where smoke will go, and the need to keep smoke away from populated areas further decreases the number of available burn days. We concluded that, in the DNF, even when burn conditions may be favorable for desired fire behavior, wind directions may not be acceptable due to the potential for smoke intrusions into populated areas. Our results indicated that many moderate weather days that would be acceptable for prescribed fire ignition would likely result in smoke intrusions into nearby communities.

Fuel moisture and winds are two of the most important factors affecting wildland fire behavior, and winds can be highly variable and unpredictable [47]. Wind speed and direction are affected by topography and vegetation and can change at time scales of hours, minutes, and even seconds [19]. Topography can directly affect fire behavior through the channeling of winds, which are typically strong along major streams incised through mountain valleys [10]. Cold air from radiation cooling at night drops into mountain valleys causing downslope winds to form [20]. Less turbulence at night further promotes winds that follow terrain. These downslope winds generally occur from sunset to sunrise [20]. This effect was evident in our analysis.

While daytime wind flows may have been in acceptable directions, there were patterns of shifting wind direction overnight that could lead to smoke intrusions. Additionally, when fuels from prescribed fires continue to burn overnight, combustion may take place in the smoldering phase, which produces large amounts of particulate matter. This smoldering can more than double the particulate emissions compared to the flaming phase $[20,48]$. Smoldering is more common in fuel types such as duff and rotten logs, which were abundant in the burn units. Additionally, there is often insufficient heat generated by fires during the smoldering phase to produce a convection column, resulting in smoke and pollutants staying near the ground and concentrating in valley bottoms [20].

\subsection{Smoke Intrusions}

The nighttime smoke dispersion modeling from the intrusions in 2014 demonstrated how shifts in wind directions, especially those that occur down the valley at night alongside reductions in wind speed, led to smoke intrusions into nearby communities despite satisfactory conditions at the time of ignition. The use of the higher-resolution meteorological model, which can better resolve complex terrain features, improved smoke dispersion predictions for the 5 October 2014 intrusion period. 
However, more case studies involving different model resolutions are needed to test the generality of this result. Higher resolutions were shown to provide improved results when compared with coarser resolutions in modeling fire danger indices [49].

The approximately 1-h lag between the observed start of the smoke intrusion and the model prediction likely resulted from errors in the wind field; lower wind speeds, wrong wind directions, or a combination thereof could have resulted in the plume ending up in Bend later. While daytime wind speeds were biased low at the Round Mountain and Tumalo Ridge RAWS locations (but high at Lava Butte) and nighttime wind speeds were biased low at the Lava Butte and Round Mountain RAWS locations (but slightly high at Tumalo Ridge), the errors ranged from 0.5 to $1.77 \mathrm{~m} \cdot \mathrm{s}^{-1}$, which indicated generally strong correspondence between the $1-\mathrm{km}$ model and the measured data. The lag was more likely attributable to the errors in wind direction, which ranged from $20^{\circ}$ to $81^{\circ}$. However, overall, the high-resolution meteorological model did a reasonably good job of capturing the timing and duration of the smoke intrusion.

We found consistently lower smoke concentrations predicted by the models than observed with deployed monitors. Ottmar et al. [28] identified smoldering consumption of duff, stumps, and basal accumulations as likely contributing substantial smoke into the atmosphere. For modeling the daytime smoke intrusions from 2015, increasing the duff depth from $5.1 \mathrm{~cm}$ to $12.7 \mathrm{~cm}$ in the model approximately doubled the pre-burn fuel load (every $2.5 \mathrm{~cm}$ of duff contributes about $27,169 \mathrm{~km} \cdot \mathrm{ha}^{-1}$ in fuel loading), with most of that in the smoldering phase causing it to be released close to the ground. This improved BlueSky's predicted concentrations, although the main plume was still simulated to miss Bend because predicted winds did not change.

Comparing the predicted and observed winds and particulate matter across the intrusions indicated conditions that were common to all but one of the intrusions. Most cases occurred during the late night and early morning hours, when winds were light or calm, and smoke movement was driven by terrain-induced down-drainage flows. This result was made evident by the repeated shifts in wind direction at night when wind speeds lowered. The unique case occurred on 4 May 2015, when daytime winds carried smoke into Bend in the early afternoon, two hours after ignition. In all cases, the prescribed fires were located southwest of Bend and smoke was transported into the city by southwest winds.

The accuracy of smoke dispersion model results varied by intrusion. In some cases, the model results showed smoke transport into Bend close to the time indicated by the observations (the daytime intrusions of 4 May, and the nighttime intrusions of 5-6 May 2015 and 5 October 2014). The model results for the other cases (28-29 May and 5-6 June 2015) did not predict smoke transport into Bend. When both the observations and the model showed smoke in Bend, the modeled concentrations were lower than observed, sometimes by an order of magnitude or more. This suggests that emissions from smoldering fuels were likely underestimated. While the E-samplers track relative concentrations of $\mathrm{PM}_{2.5}$ and may tend to underestimate them, the modeled concentrations were still consistently lower than the observed values.

Furthermore, dispersion models are only as good as the underlying meteorological model [3] and, if that model does not accurately represent the winds (such as sub-grid scale drainage winds and flow through vegetative cover), the dispersion model will not accurately transplant the smoke. Our results indicated that wind shifts occurring overnight were not adequately captured by the meteorological models. Moreover, the 4-km-resolution WRF data generally overpredicted surface wind speeds, a known model behavior [50-57]. While our analysis used hourly data instead of higher-temporal-resolution data to drive BlueSky, the temporal variability of meteorological conditions in complex terrain can be substantial. We acknowledge this limitation; however, 1-h data are representative of what land managers and air-quality personnel use and, thus, provide a better real-world context for the ability to predict smoke intrusions.

Improved fuel estimates can be included in BlueSky; yet, in this case, the results were fundamentally impacted by the modeled winds not going in the right direction. Wind direction mean errors ranged 
from $14-94^{\circ}$ with even higher mean errors during the night. For the one intrusion where two resolutions were available (4 October 2014, $4 \mathrm{~km}$ and $1 \mathrm{~km}$ ), the higher-resolution model better predicted the location and timing of the smoke intrusion. That said, the higher-resolution NAM simulations did not result in consistently smaller wind direction errors than the lower-resolution WRF simulations. It was unclear why this was the case. Both the Lava Butte and Round Mountain locations are situated at higher elevations and probably reflect more synoptic flows, while the Tumalo Ridge location (lower elevation, closer to Bend) is what local managers generally use as representative of burn units. The lower error at night at the Tumalo Ridge location was probably key for the improved modeling in this comparison.

Many factors can impact the meteorology that is important for fire behavior and smoke transport/dispersion. The meteorological models used in this analysis take into account topography and broad-scale vegetative cover but not the influence of local vegetation on circulation in the modeling. The WRF and NAM models are not able to resolve flows through vegetation layers, a drawback to using these meteorological data for doing comprehensive assessments of topography and vegetation impacts on circulations and smoke dispersion, particularly local near-surface circulations and dispersion. Forest vegetation can alter the distribution of turbulent kinetic energy and turbulent heat and momentum fluxes, thereby influencing boundary- and surface-layer structure and affecting the local and within-canopy transport and diffusion of smoke $[58,59]$. This is particularly important for low-intensity surface fires-like many prescribed fires-and implementing fully resolved canopy sub-models within atmospheric models may improve predictions of local smoke effects [60]. However, even in cases where winds are forecasted well, it is important to include site-specific fuel loadings in order to improve predicted $\mathrm{PM}_{2.5}$ concentrations. Emphasis on capturing the number of stumps and rotten logs, as well as duff depth, may improve predictions of $\mathrm{PM}_{2.5}$ concentrations in the region since these components contribute substantially to nighttime smoke.

\subsection{Future Directions}

Smoke intrusions to populated areas and related concerns from prescribed fires are likely to persist even with better modeling tools and improved understanding of local meteorological patterns. However, site-specific characterization of the smoldering fuels and using higher-resolution meteorological data both improved the smoke modeling results in this analysis. Future research is needed in order to improve the characterization of pre-fire fuel loading and to refine the measurement of the consumption of forest fuels during the flaming and smoldering phases of combustion, as well as the timing and the duration of that consumption. Additionally, continued improvement of meteorological models is critical to predicting the delivery of smoke to correct locations. High-resolution model output shows promise for areas of complex terrain.

Accurate assessments of fuel types and loadings are essential for realistic estimates of emissions. Unfortunately, current fuel models do not adequately represent the smoldering fuels that often are responsible for smoke intrusions in this region. Furthermore, smoke dispersion models contain inherent uncertainties and limitations in their ability to correctly predict the directionality, timing, and concentration of smoke. While this study mainly addressed errors in the meteorological model inputs and, in one case, attempted to reduce the impact of non-site-specific fuel loadings, there are additional potential sources of error. Even when site-specific fuel loadings (including specific fuel loadings in each size class) are available, differences exist in how specific consumption models treat those internally [35]. The largest difference between consumption models is in the allocation of consumption between smoldering and flaming phases of combustion and in the consumption of certain fuel strata (such as canopy, shrubs, herbaceous, and duff) [37]. There are also uncertainties in the in-plume chemical processes, plume rise, emission factors, fire size and type, and time profiles specifying how emissions are distributed throughout the day [37]. Research addressing these issues and improving the behavior of smoke and emissions models is ongoing. 
For fire and fuel managers, it may no longer be enough to base prescribed fire plans on the total amount of forest fuels, fuel consumption, and total smoke produced on site. Rather, a more detailed understanding of the timing of consumption and smoke production during periods of weak atmospheric dispersal may better help manage downwind smoke effects in communities near the WUI. Furthermore, knowledge of the general meteorological patterns and how potential burn days vary by season and location can help with planning when and where to conduct prescribed fires.

\section{Conclusions}

This study assessed six smoke intrusion episodes in the autumn of 2014 and spring of 2015 in Bend, Oregon. On average, there were 26-28 days per year with suitable meteorological conditions for prescribed fire behavior, including 1-6 days per month in the spring and 2-4 days per month in the fall. Wind direction further constrained the predicted number of acceptable burn days due to the potential for smoke dispersal into city centers. Of the days meeting the general meteorological parameters for prescribed fire, ideal wind conditions occurred on $13 \%$ of days in the spring and on $5 \%$ of days in the fall. Additionally, our results demonstrated the utility of dispersion modeling for predicting smoke intrusions. However, considerable errors in wind speed and direction of the meteorological models may produce poor model results and cause mischaracterization of smoke intrusion events. In the case study assessed here, the results of the higher-resolution meteorological and dispersion model showed their potential for improving the prediction of both timing and location of smoke intrusions. Using the 1-km-resolution North American Mesoscale Forecast System (NAM) model resulted in a predicted smoke intrusion within $1 \mathrm{~h}$ of the observed event, albeit with lower predicted concentrations. Finally, this study highlights the difficulty of planning and implementing prescribed fires in a region where complex terrain, vegetation, and weather patterns severely limit conditions for smoke dispersal that would avoid health and safety impacts to nearby communities.

Author Contributions: Conceptualization, M.R. and S.O.; methodology, C.M., M.R., and S.O.; software, C.M. and S.O.; validation, C.M., M.R., and S.O.; formal analysis, C.M., M.R., and S.O.; investigation, C.M., M.R., and S.O.; resources, M.R., S.O., and E.A.; data curation, C.M. and S.O.; writing-original draft preparation, C.M. and S.O.; writing-review and editing, C.M., M.R., and S.O.; visualization, C.M. and S.O.; supervision, M.R. and S.O.; project administration, M.R., S.O., and E.A.; funding acquisition, M.R., S.O., and E.A.

Funding: This research was funded by USDA Forest Service Region 6 and the Washington and Oregon Offices of the Bureau of Land Management.

Acknowledgments: We thank Rick Graw for conceptualizing the project, helping secure funds, and designing and supporting the field campaigns. We also would like to thank the many people who made this study possible, including everyone at the Deschutes National Forest Supervisors Office, especially Deana Wall for her efforts coordinating with the local community, as well as Jinny Reed and others at the USDA Forest Service Sisters, Oregon Regional Office, Bridges Boys Academy, Cascade Academy, Miller Elementary, Cascade Middle School, Tumalo Golf Club, Colin Wills with Arnold Irrigation District, and Jason Schneider with the Sunriver Home Owners Association.

Conflicts of Interest: The authors declare no conflict of interest. The funders worked collaboratively with the authors to define the problem for study. Subsequent collection, analysis, and interpretation of the data, writing of the manuscript, and decision to publish the results were done independent of any involvement by the funders. 


\section{Appendix A}

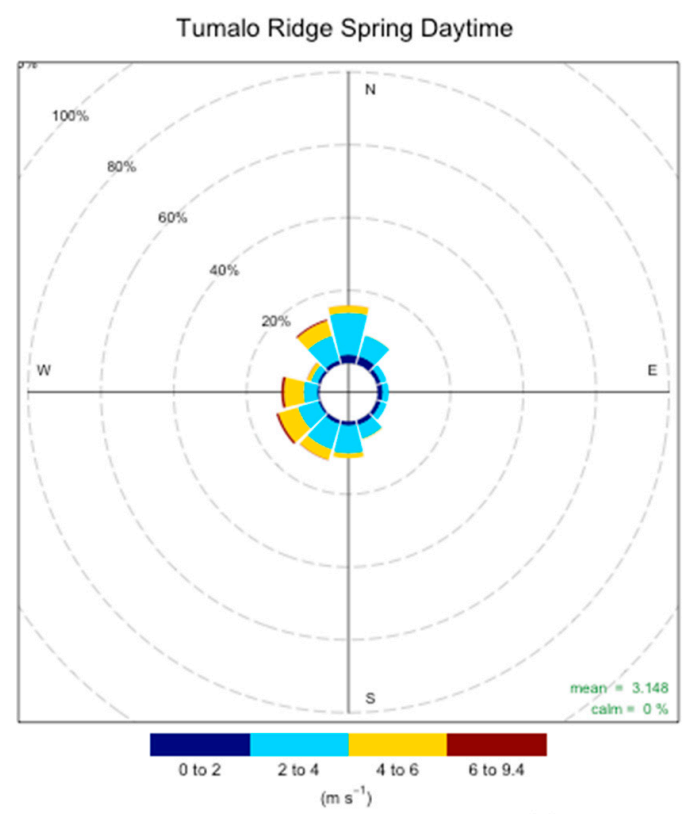

Frequency of counts by wind direction (\%)

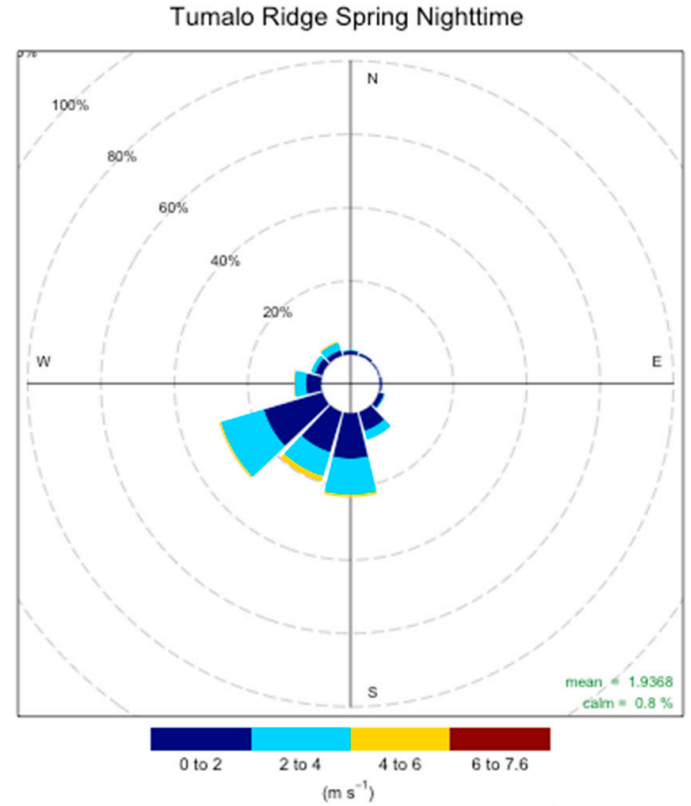

Frequency of counts by wind direction (\%)

Figure A1. Wind roses for Tumalo Ridge in the spring during the daytime (left) and nighttime (right).
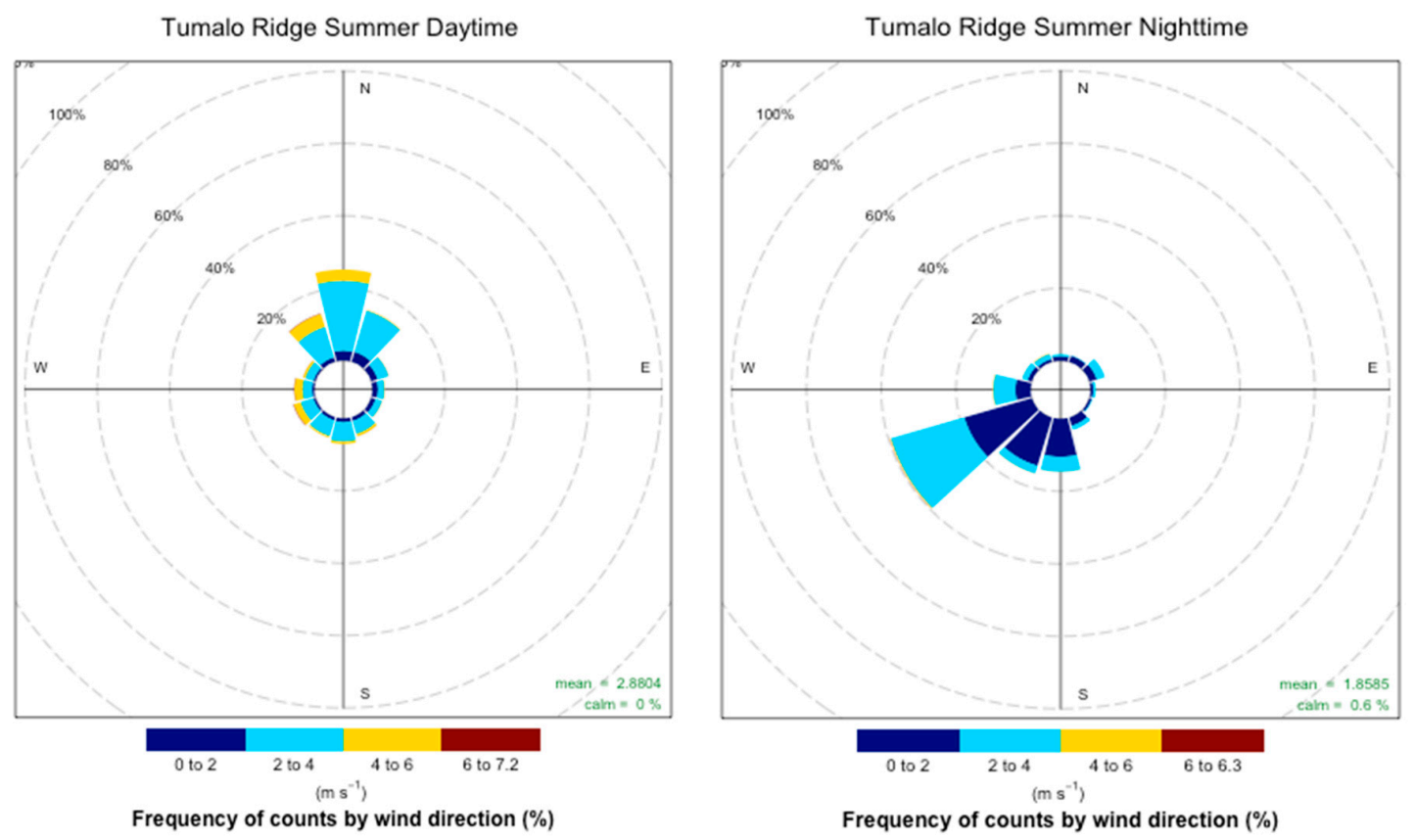

Figure A2. Wind roses for Tumalo Ridge in the summer during the daytime (left) and nighttime (right). 

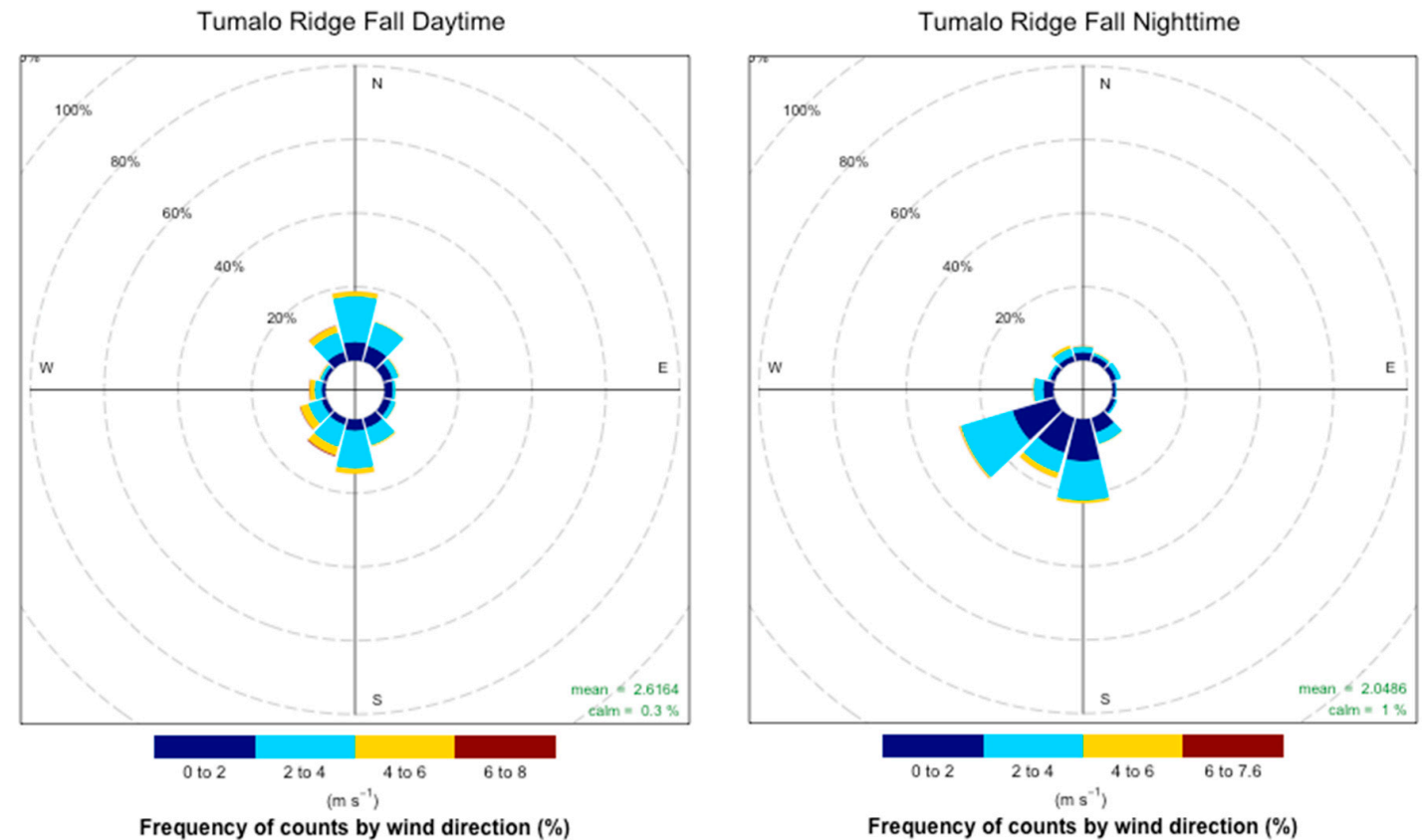

Figure A3. Wind roses for Tumalo Ridge in the fall during the daytime (left) and nighttime (right).
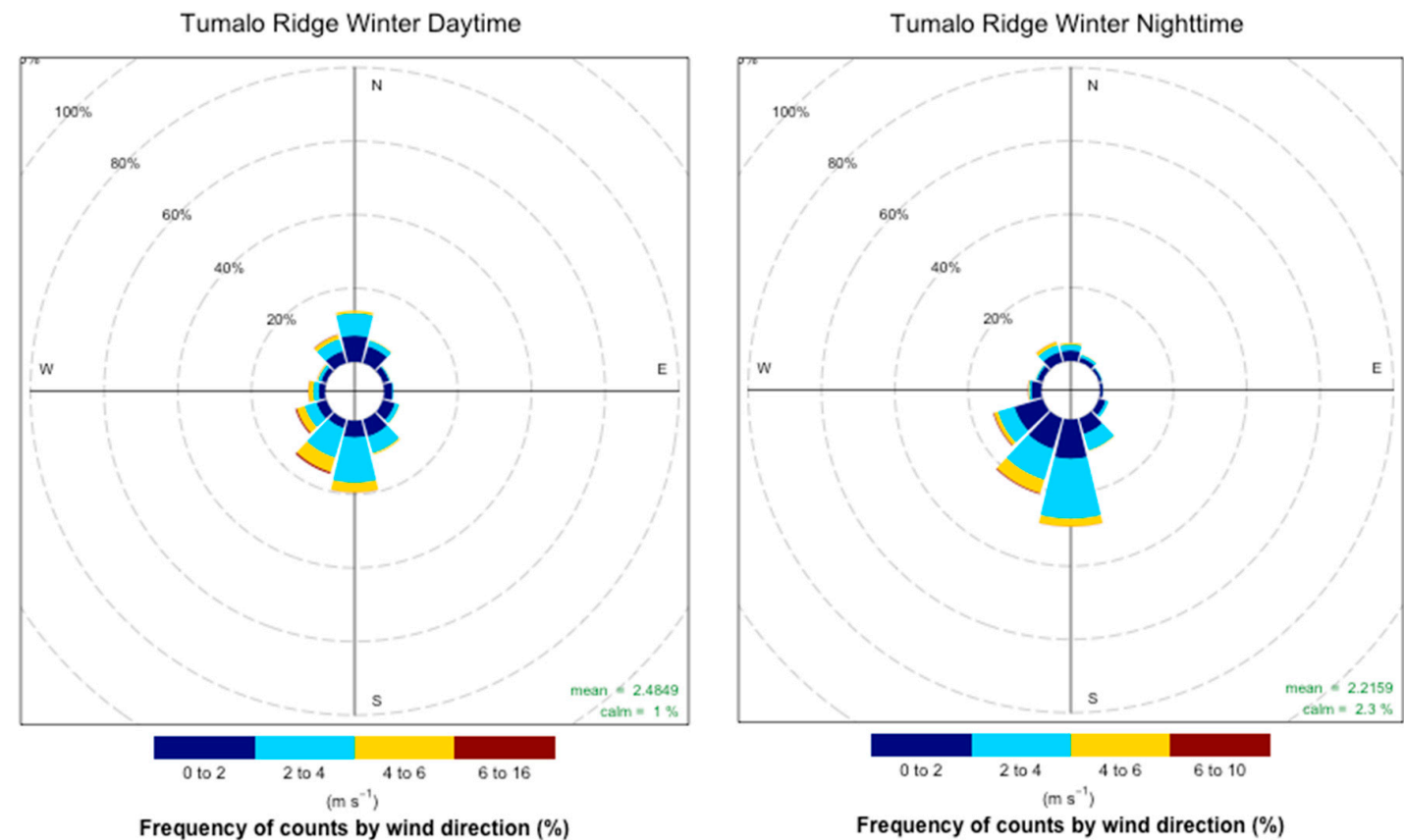

Figure A4. Wind roses for Tumalo Ridge in the winter during the daytime (left) and nighttime (right). 


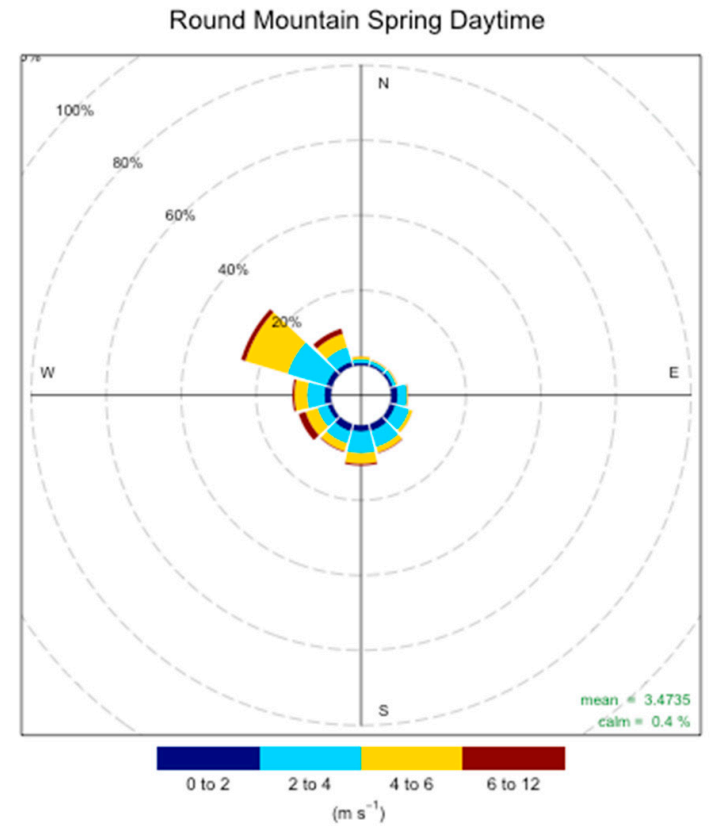

Frequency of counts by wind direction $(\%)$

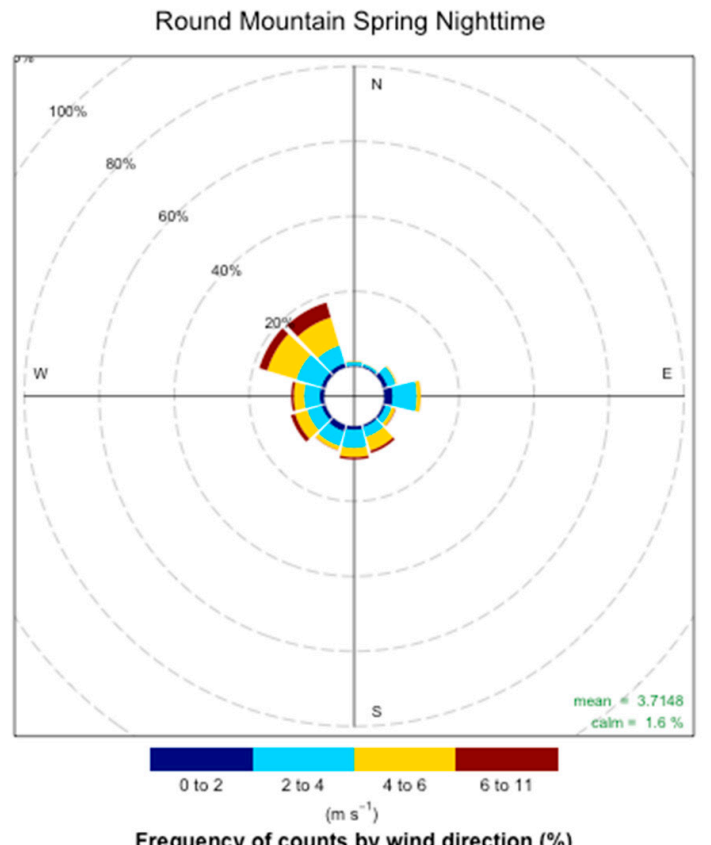

Frequency of counts by wind direction $(\%)$

Figure A5. Wind roses for Round Mountain in the spring during the daytime (left) and nighttime (right).

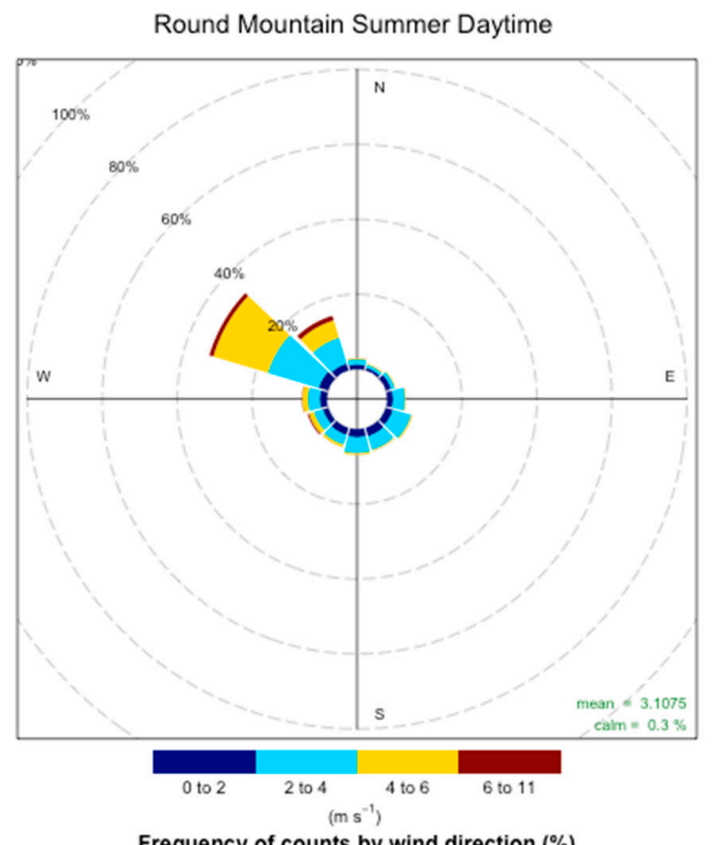

Frequency of counts by wind direction (\%)

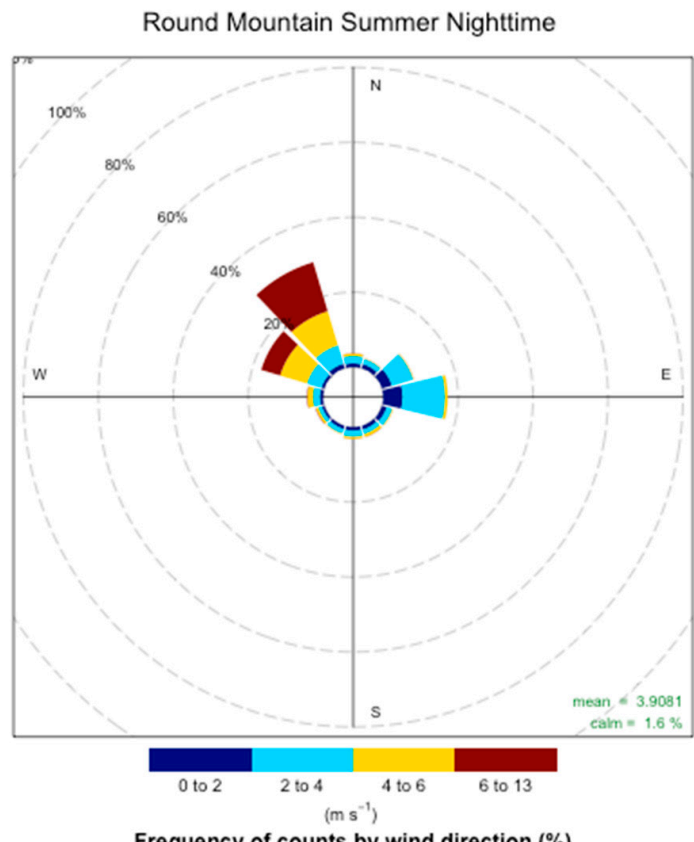

Frequency of counts by wind direction $(\%)$

Figure A6. Wind roses for Round Mountain in the summer during the daytime (left) and nighttime (right). 

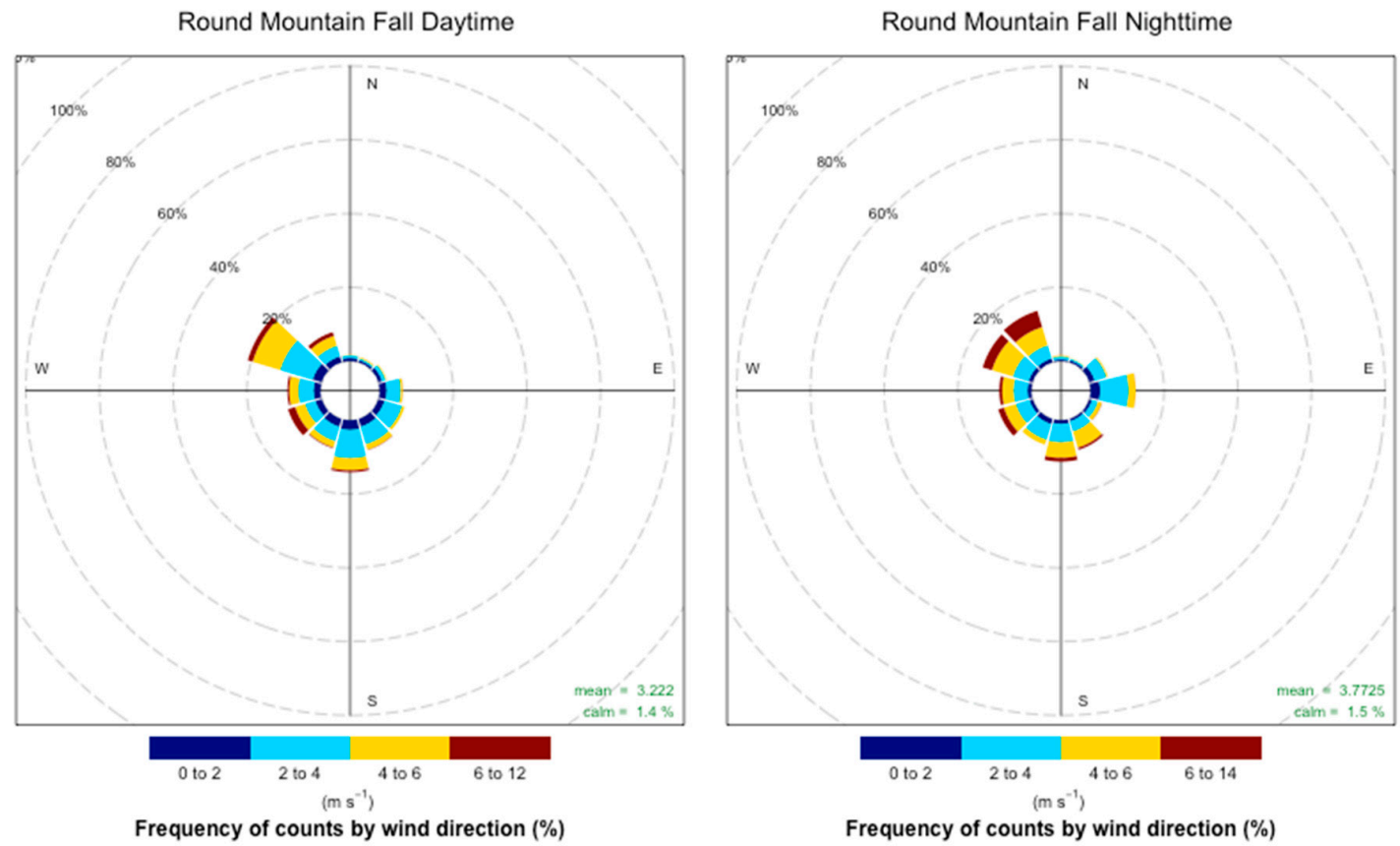

Figure A7. Wind roses for Round Mountain in the fall during the daytime (left) and nighttime (right).
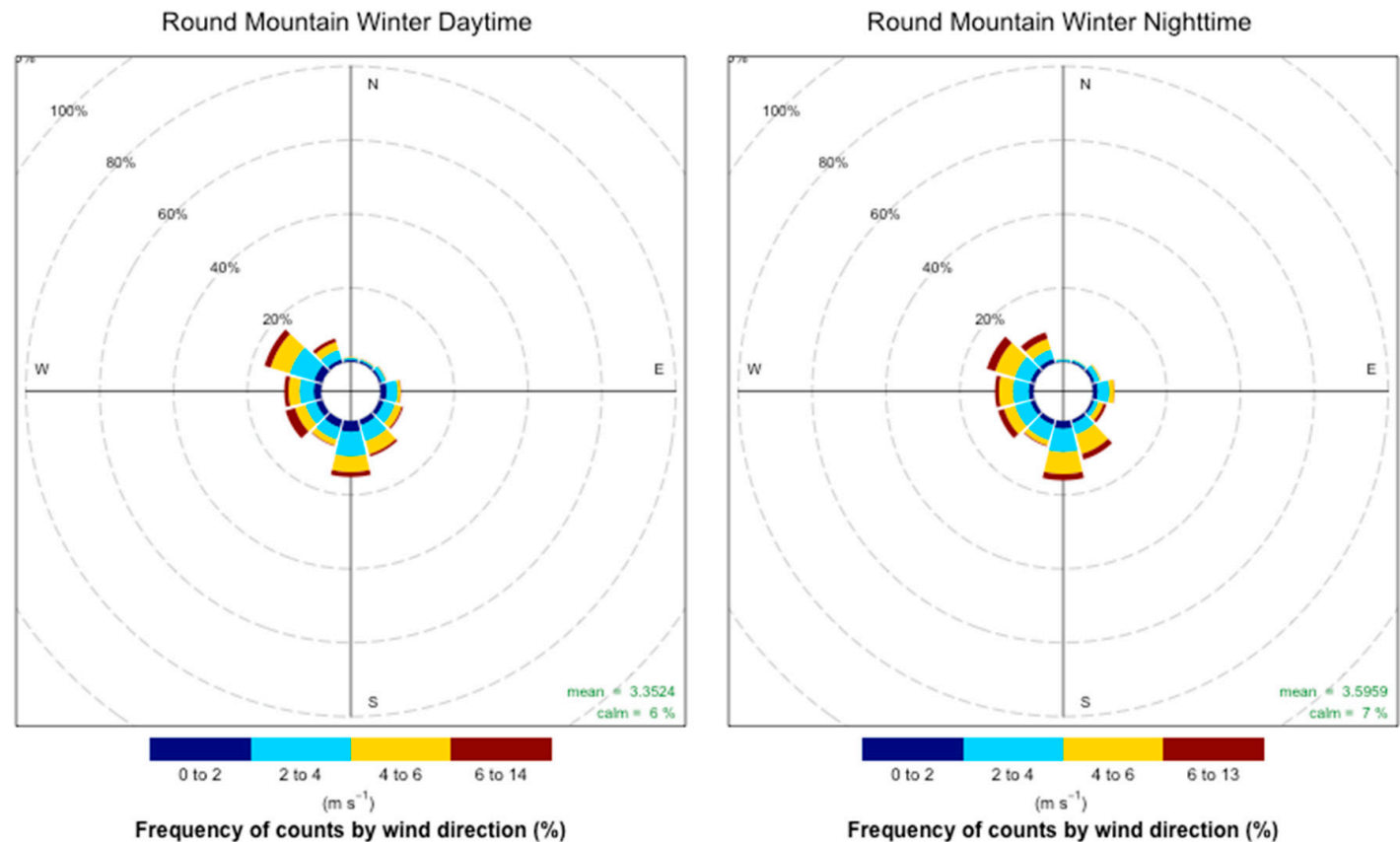

Figure A8. Wind roses for Round Mountain in the winter during the daytime (left) and nighttime (right). 
Lava Butte Spring Daytime

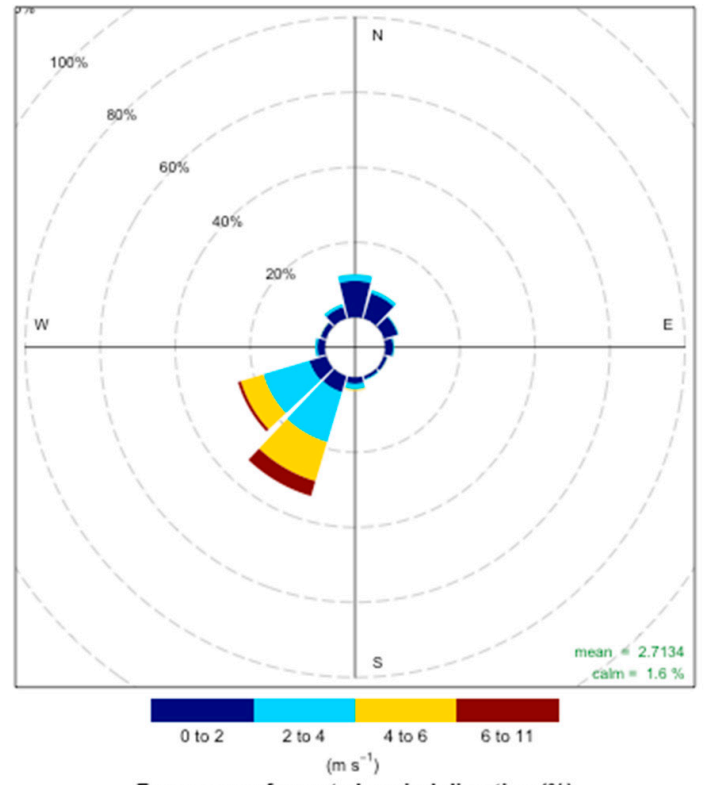

Frequency of counts by wind direction (\%)
Lava Butte Spring Nighttime

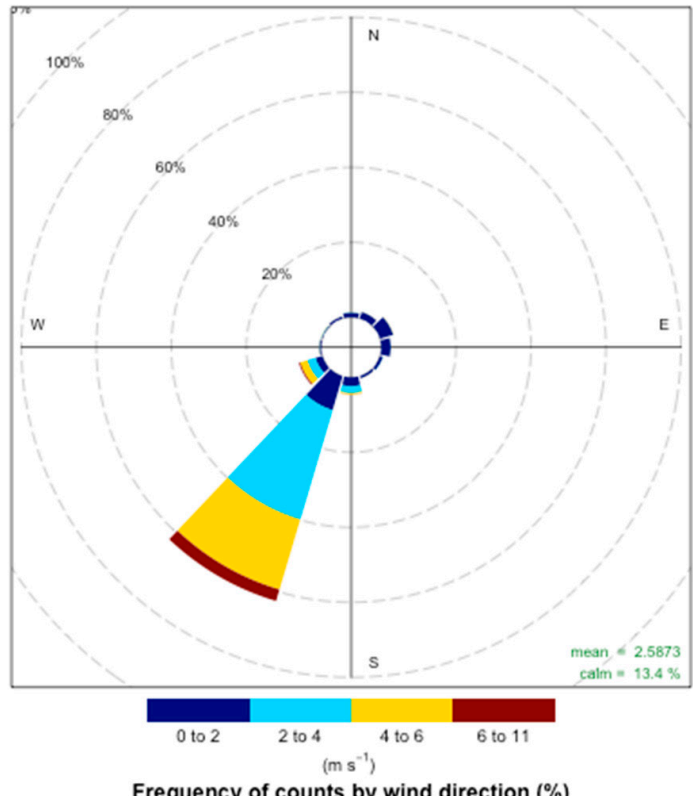

Frequency of counts by wind direction (\%)

Figure A9. Wind roses for Lava Butte in the spring during the daytime (left) and nighttime (right).
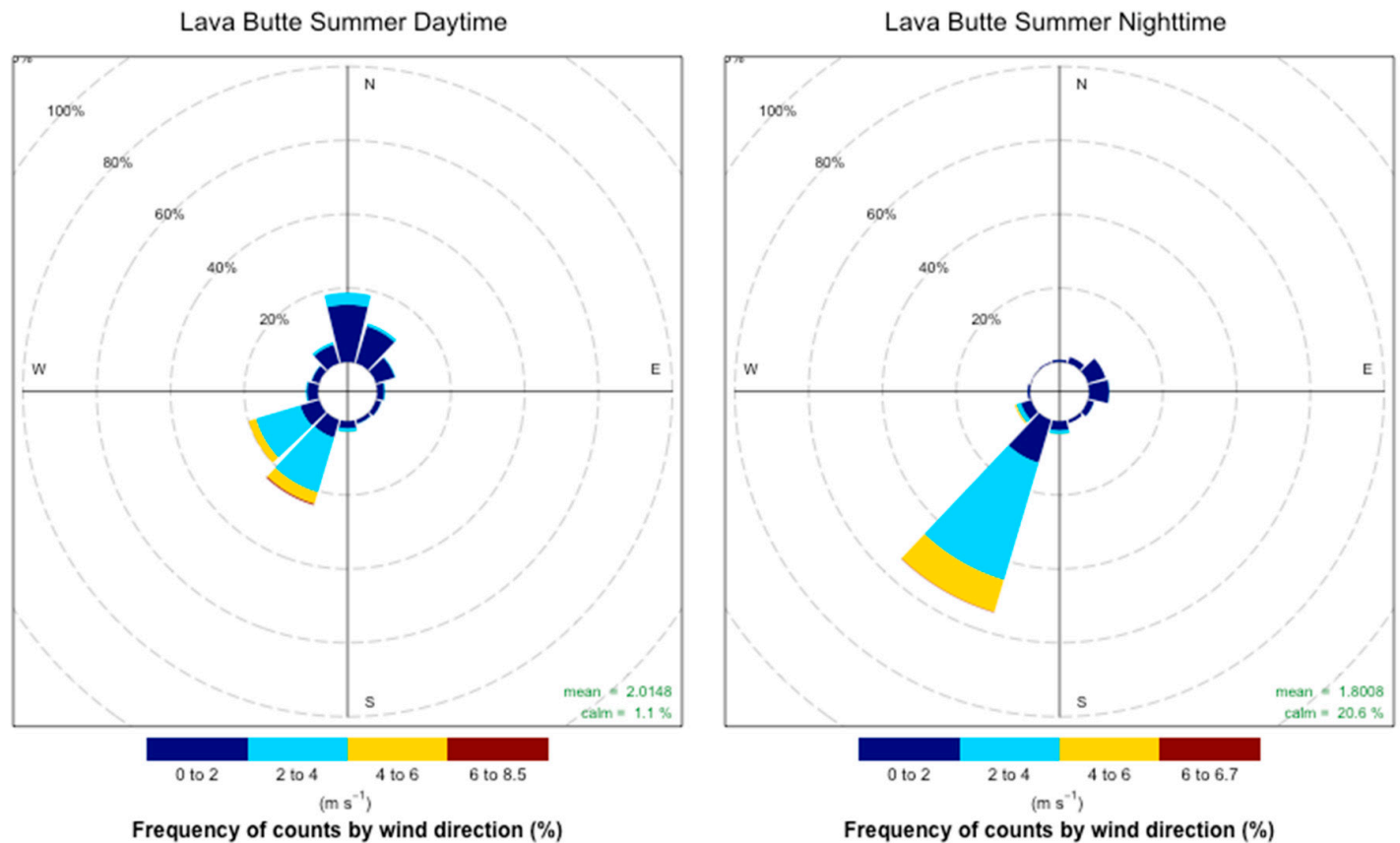

Figure A10. Wind roses for Lava Butte in the summer during the daytime (left) and nighttime (right). 

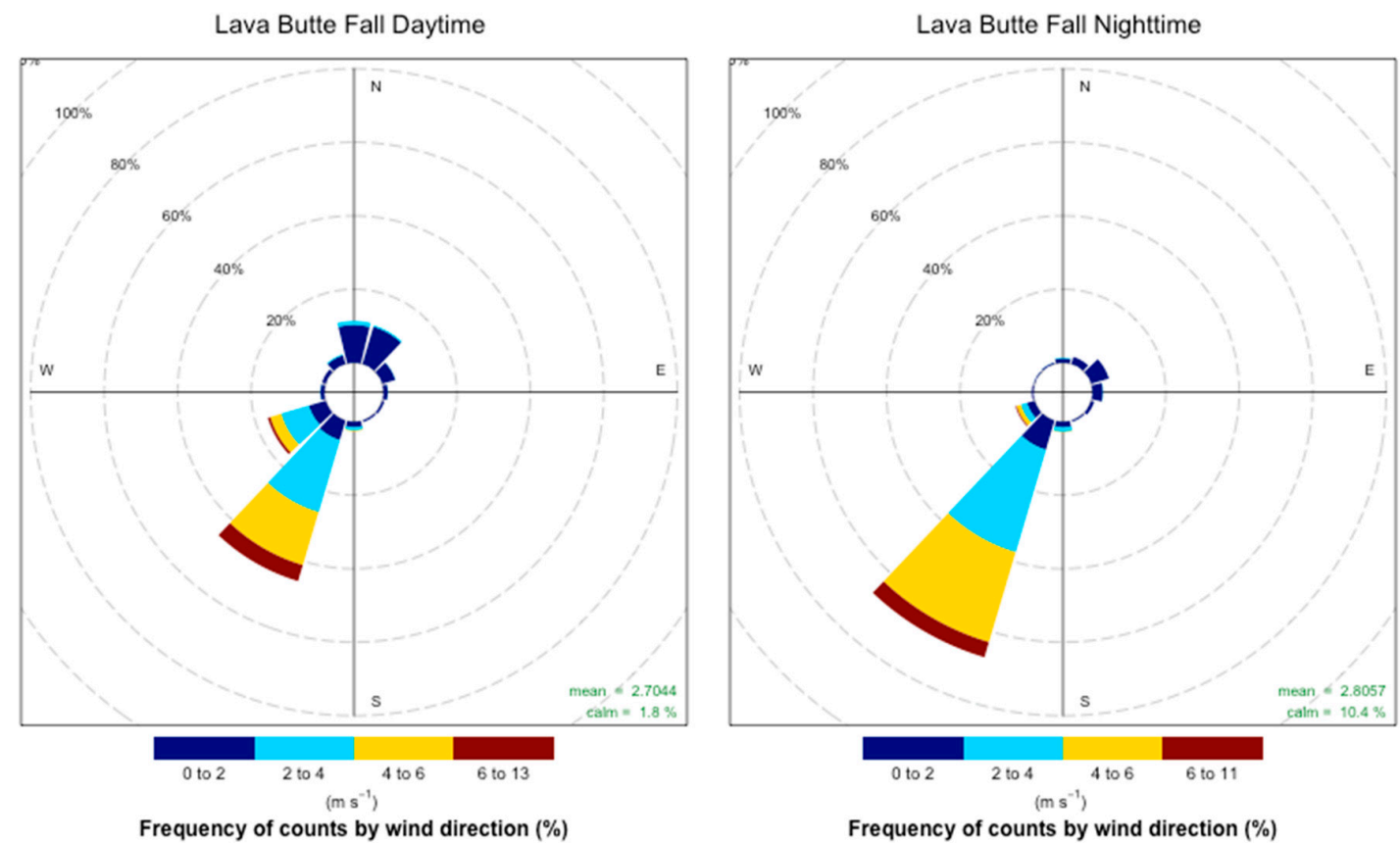

Figure A11. Wind roses for Lava Butte in the fall during the daytime (left) and nighttime (right).
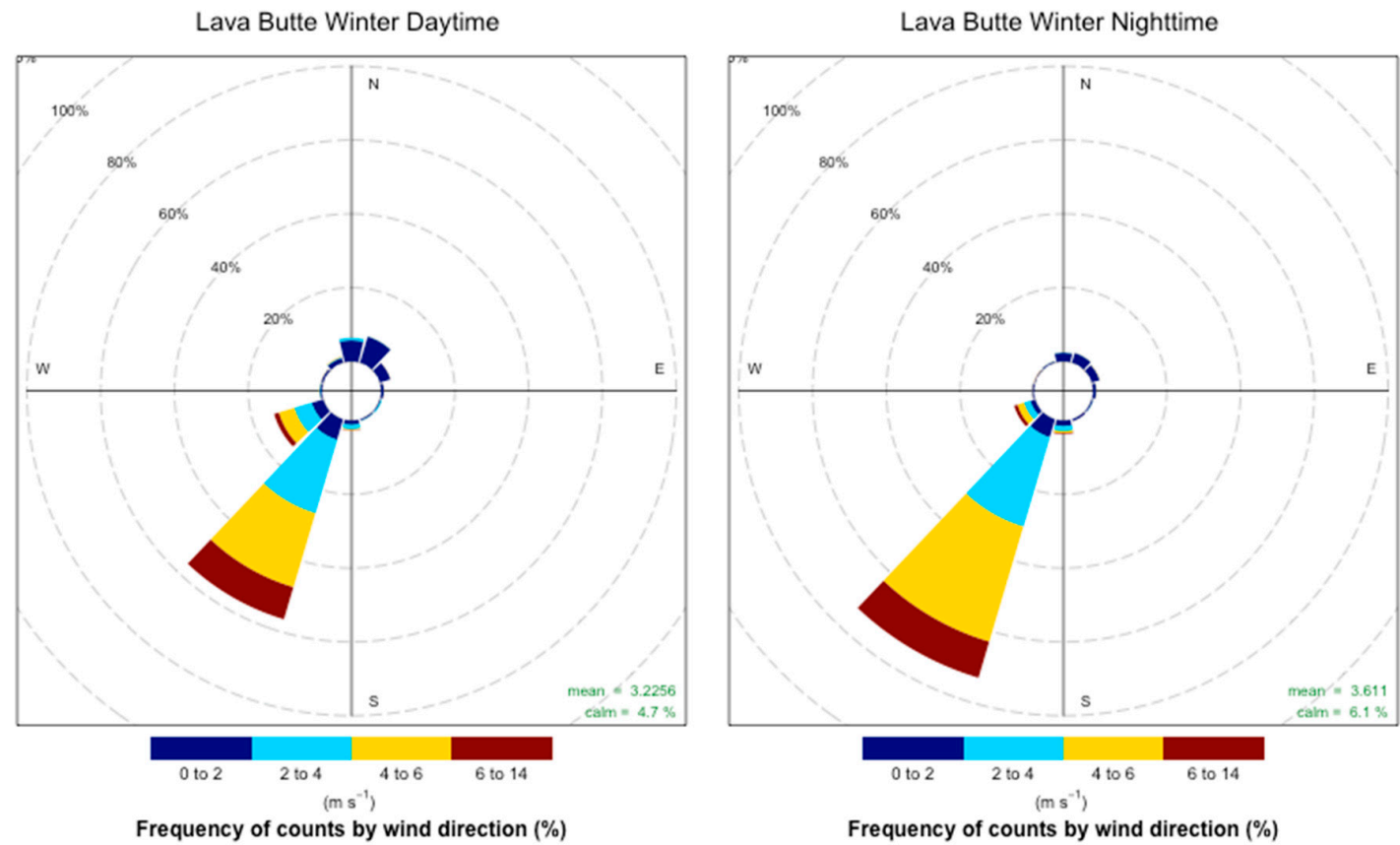

Figure A12. Wind roses for Lava Butte in the winter during the daytime (left) and nighttime (right). 


\section{Appendix B}

Table A1. Wind speed bias and error, wind direction error, and percentage of calm observations for day and night on 4 October 2014. Model data are from the 1-km-resolution North American Mesoscale Forecast System (NAM) model operated by the National Centers for Environmental Prediction and the 4-km-resolution Weather Research and Forecasting (WRF) model operated by the University of Washington. Locations are listed from north to south. RAWS = remote automated weather station; WS $=$ wind speed; $\mathrm{WD}=$ wind direction. Calm winds indicate values under $0.25 \mathrm{~m} \cdot \mathrm{s}^{-1}$.

\begin{tabular}{|c|c|c|c|c|c|c|c|}
\hline $\begin{array}{c}\text { Meteorological } \\
\text { Model }\end{array}$ & Location & $\begin{array}{c}\text { Station } \\
\text { Type }\end{array}$ & Time & $\begin{array}{l}\text { WS Bias } \\
\left(\mathrm{m} \cdot \mathrm{s}^{-1}\right)\end{array}$ & $\begin{array}{l}\text { WS Error } \\
\left(\mathrm{m} \cdot \mathrm{s}^{-1}\right)\end{array}$ & $\begin{array}{l}\text { WD Error } \\
\left({ }^{\circ}\right)\end{array}$ & $\%$ Calm \\
\hline \multirow[t]{2}{*}{ 1-km NAM } & Lava & RAWS & Day & 0.18 & 0.50 & 81.48 & $25 \%$ \\
\hline & Butte & & Night & -0.35 & 0.64 & 20.39 & $0 \%$ \\
\hline \multirow[t]{2}{*}{ 1-km NAM } & Round & RAWS & Day & -1.77 & 1.77 & 45.99 & $0 \%$ \\
\hline & Mountain & & Night & -0.75 & 1.19 & 80.49 & $0 \%$ \\
\hline \multirow[t]{2}{*}{ 1-km NAM } & Tumalo & RAWS & Day & -1.17 & 1.22 & 55.46 & $0 \%$ \\
\hline & Ridge & & Night & 0.24 & 0.51 & 36.40 & $0 \%$ \\
\hline \multirow[t]{2}{*}{ 4-km WRF } & Lava & RAWS & Day & 0.21 & 0.35 & 50.86 & $25 \%$ \\
\hline & Butte & & Night & 0.19 & 0.74 & 8.99 & $0 \%$ \\
\hline \multirow[t]{2}{*}{ 4-km WRF } & Round & RAWS & Day & -1.58 & 1.60 & 60.88 & $0 \%$ \\
\hline & Mountain & & Night & -0.84 & 1.36 & 84.46 & $0 \%$ \\
\hline \multirow[t]{2}{*}{ 4-km WRF } & Tumalo & RAWS & Day & -1.03 & 1.03 & 35.13 & $0 \%$ \\
\hline & Ridge & & Night & 0.01 & 0.59 & 92.62 & $0 \%$ \\
\hline
\end{tabular}

Table A2. Wind speed bias and error, wind direction error, and percentage of calm observations for 4 May 2015. Model data are from the 4-km-resolution Weather Research and Forecasting (WRF) model operated by the University of Washington. Locations are listed from north to south. WX = WatchDog meteorological measurement station; $\mathrm{PM}_{2.5}=$ Met One Instruments, Inc. E-Sampler; RAWS = remote automated weather station; $\mathrm{WS}=$ wind speed; $\mathrm{WD}=$ wind direction. Calm winds indicate values under $0.25 \mathrm{~m} \cdot \mathrm{s}^{-1}$.

\begin{tabular}{|c|c|c|c|c|c|}
\hline Location & Station Type & $\begin{array}{c}\text { WS Bias } \\
\left(\mathrm{m} \cdot \mathrm{s}^{-1}\right)\end{array}$ & $\begin{array}{l}\text { WS Error } \\
\left(\mathrm{m} \cdot \mathrm{s}^{-1}\right)\end{array}$ & $\begin{array}{l}\text { WD Error } \\
\left({ }^{\circ}\right)\end{array}$ & $\%$ Calm \\
\hline $\begin{array}{l}\text { Sisters Ranger } \\
\text { Station }\end{array}$ & WX & 4.99 & 4.99 & 31.58 & $13 \%$ \\
\hline $\begin{array}{l}\text { Bridges Boys } \\
\text { Academy }\end{array}$ & WX & 2.02 & 2.02 & 43.07 & $0 \%$ \\
\hline Cascade Academy & WX & 2.16 & 2.16 & 49.95 & $38 \%$ \\
\hline Tumalo Ridge & RAWS & 2.07 & 2.07 & 17.35 & $0 \%$ \\
\hline $\begin{array}{l}\text { Cascade Middle } \\
\text { School }\end{array}$ & $\mathrm{PM}_{2.5}$ & 0.54 & 0.85 & 42.04 & $0 \%$ \\
\hline Lava Butte & RAWS & 1.93 & 1.93 & 18.53 & $0 \%$ \\
\hline Sunriver & $\mathrm{PM}_{2.5}$ & - & - & - & $100 \%$ \\
\hline Round Mountain & RAWS & 1.58 & 1.58 & 7.56 & $0 \%$ \\
\hline
\end{tabular}


Table A3. Wind speed bias and error, wind direction error, and percentage of calm observations for day and night on 5 May 2015. Model data are from the 4-km-resolution Weather Research and Forecasting (WRF) model operated by the University of Washington. Locations are listed from north to south. $\mathrm{WX}=$ WatchDog meteorological measurement station; $\mathrm{PM}_{2.5}=$ Met One Instruments, Inc. E-Sampler; RAWS = remote automated weather station; $W S=$ wind speed; $W D=$ wind direction. Calm winds indicate values under $0.25 \mathrm{~m} \cdot \mathrm{s}^{-1}$.

\begin{tabular}{|c|c|c|c|c|c|c|}
\hline Location & $\begin{array}{c}\text { Station } \\
\text { Type }\end{array}$ & Time & $\begin{array}{l}\text { WS Bias } \\
\left(\mathrm{m} \cdot \mathrm{s}^{-1}\right)\end{array}$ & $\begin{array}{l}\text { WD Bias } \\
\left(\mathrm{m} \cdot \mathrm{s}^{-1}\right)\end{array}$ & $\begin{array}{l}\text { WD Error } \\
\left({ }^{\circ}\right)\end{array}$ & $\%$ Calm \\
\hline \multirow{2}{*}{$\begin{array}{l}\text { Sisters } \\
\text { Ranger } \\
\text { Station }\end{array}$} & \multirow[t]{2}{*}{$W X$} & Day & 3.88 & 3.88 & 27.45 & $25 \%$ \\
\hline & & Night & Calm & Calm & Calm & $100 \%$ \\
\hline \multirow{2}{*}{$\begin{array}{l}\text { Bridges } \\
\text { Boys } \\
\text { Academy }\end{array}$} & \multirow[t]{2}{*}{$W X$} & Day & 1.66 & 1.66 & 38.34 & $0 \%$ \\
\hline & & Night & 1.30 & 1.30 & Calm & $86 \%$ \\
\hline \multirow[t]{2}{*}{$\begin{array}{l}\text { Cascade } \\
\text { Academy }\end{array}$} & \multirow[t]{2}{*}{$W X$} & Day & 2.14 & 2.14 & 46.67 & $13 \%$ \\
\hline & & Night & Calm & Calm & Calm & $100 \%$ \\
\hline \multirow[t]{2}{*}{$\begin{array}{l}\text { Miller } \\
\text { Elementary }\end{array}$} & \multirow[t]{2}{*}{$W X$} & Day & 1.20 & 1.40 & 27.29 & $0 \%$ \\
\hline & & Night & 1.13 & 1.13 & Calm & $86 \%$ \\
\hline \multirow{2}{*}{$\begin{array}{l}\text { Tumalo } \\
\text { Ridge }\end{array}$} & \multirow[t]{2}{*}{ RAWS } & Day & 0.40 & 0.72 & 30.83 & $0 \%$ \\
\hline & & Night & -0.47 & 0.50 & 51.13 & $0 \%$ \\
\hline \multirow{2}{*}{$\begin{array}{l}\text { Cascade } \\
\text { Middle } \\
\text { School }\end{array}$} & \multirow[t]{2}{*}{$\mathrm{PM}_{2.5}$} & Day & 0.92 & 0.92 & 29.58 & $0 \%$ \\
\hline & & Night & 0.16 & 0.25 & 107.52 & $0 \%$ \\
\hline \multirow[t]{2}{*}{ Lava Butte } & \multirow[t]{2}{*}{ RAWS } & Day & 2.48 & 2.48 & 33.71 & $0 \%$ \\
\hline & & Night & -1.07 & 1.53 & Calm & $57 \%$ \\
\hline \multirow[t]{2}{*}{ Sunriver } & \multirow[t]{2}{*}{$\mathrm{PM}_{2.5}$} & Day & -1.56 & 1.64 & 63.74 & $0 \%$ \\
\hline & & Night & 0.00 & 0.73 & 123.69 & $0 \%$ \\
\hline \multirow[t]{2}{*}{$\begin{array}{l}\text { Round } \\
\text { Mountain }\end{array}$} & \multirow[t]{2}{*}{ RAWS } & Day & 1.27 & 1.27 & 7.69 & $0 \%$ \\
\hline & & Night & -0.71 & 0.87 & 14.19 & $0 \%$ \\
\hline
\end{tabular}

Table A4. Wind speed bias and error, wind direction error, and percentage of calm observations for day and night on 28 May 2015. Model data are from the 4-km-resolution Weather Research and Forecasting (WRF) model operated by the University of Washington. Locations are listed from north to south. $\mathrm{WX}=$ WatchDog meteorological measurement station; $\mathrm{PM}_{2.5}=$ Met One Instruments, Inc. E-Sampler; RAWS = remote automated weather station; $W S=$ wind speed; $W D=$ wind direction. Calm winds indicate values under $0.25 \mathrm{~m} \cdot \mathrm{s}^{-1}$.

\begin{tabular}{|c|c|c|c|c|c|c|}
\hline Location & $\begin{array}{c}\text { Station } \\
\text { Type }\end{array}$ & Time & $\begin{array}{l}\text { WS Bias } \\
\left(\mathrm{m} \cdot \mathrm{s}^{-1}\right)\end{array}$ & $\begin{array}{l}\text { WS Error } \\
\left(\mathrm{m} \cdot \mathrm{s}^{-1}\right)\end{array}$ & $\begin{array}{l}\text { WD Error } \\
\left({ }^{\circ}\right)\end{array}$ & $\%$ Calm \\
\hline \multirow{2}{*}{$\begin{array}{l}\text { Sisters } \\
\text { Ranger } \\
\text { Station }\end{array}$} & $W X$ & Day & 2.01 & 2.01 & Calm & $75 \%$ \\
\hline & & Night & Calm & Calm & Calm & $100 \%$ \\
\hline
\end{tabular}


Table A4. Cont.

\begin{tabular}{|c|c|c|c|c|c|c|}
\hline Location & $\begin{array}{c}\text { Station } \\
\text { Type }\end{array}$ & Time & $\begin{array}{c}\text { WS Bias } \\
\left(\mathrm{m} \cdot \mathrm{s}^{-1}\right)\end{array}$ & $\begin{array}{l}\text { WS Error } \\
\left(\mathbf{m} \cdot \mathbf{s}^{-1}\right)\end{array}$ & $\begin{array}{l}\text { WD Error } \\
\left({ }^{\circ}\right)\end{array}$ & $\%$ Calm \\
\hline \multirow{3}{*}{$\begin{array}{l}\text { Bridges } \\
\text { Boys } \\
\text { Academy }\end{array}$} & \multirow{3}{*}{$W X$} & & & & & \\
\hline & & Day & 1.08 & 1.35 & 51.25 & $0 \%$ \\
\hline & & Night & Calm & Calm & Calm & $100 \%$ \\
\hline \multirow{2}{*}{$\begin{array}{l}\text { Cascade } \\
\text { Academy }\end{array}$} & \multirow[t]{2}{*}{$W X$} & Day & 1.29 & 1.29 & 50.08 & $25 \%$ \\
\hline & & Night & Calm & Calm & Calm & $100 \%$ \\
\hline \multirow{2}{*}{$\begin{array}{l}\text { Miller } \\
\text { Elementary }\end{array}$} & \multirow[t]{2}{*}{$W X$} & Day & 2.26 & 2.26 & 49.34 & $50 \%$ \\
\hline & & Night & 0.06 & 0.06 & Calm & $86 \%$ \\
\hline \multirow[t]{2}{*}{$\begin{array}{l}\text { Tumalo } \\
\text { Ridge }\end{array}$} & \multirow[t]{2}{*}{ RAWS } & Day & 0.91 & 0.95 & 54.46 & $0 \%$ \\
\hline & & Night & 0.00 & 0.94 & 93.37 & $0 \%$ \\
\hline \multirow[t]{2}{*}{$\begin{array}{l}\text { Cascade } \\
\text { Middle } \\
\text { School }\end{array}$} & \multirow[t]{2}{*}{$\mathrm{PM}_{2.5}$} & Day & 0.48 & 0.60 & 61.93 & $0 \%$ \\
\hline & & Night & 0.02 & 1.16 & 108.17 & $0 \%$ \\
\hline \multirow[t]{2}{*}{ Lava Butte } & \multirow[t]{2}{*}{ RAWS } & Day & 1.47 & 1.47 & 25.94 & $0 \%$ \\
\hline & & Night & -0.55 & 0.87 & Calm & $57 \%$ \\
\hline \multirow[t]{2}{*}{ Sunriver } & \multirow{2}{*}{$\mathrm{PM}_{2.5}$} & Day & -0.30 & 1.13 & 68.54 & $0 \%$ \\
\hline & & Night & 0.82 & 1.31 & 125.68 & $0 \%$ \\
\hline \multirow{2}{*}{$\begin{array}{l}\text { Round } \\
\text { Mountain }\end{array}$} & \multirow[t]{2}{*}{ RAWS } & Day & 1.18 & 1.30 & 74.58 & $0 \%$ \\
\hline & & Night & -1.37 & 1.37 & 86.29 & $0 \%$ \\
\hline
\end{tabular}

Table A5. Wind speed bias and error, wind direction error, and percentage of calm observations for day and night on 5 June 2015. Model data are from the 4-km-resolution Weather Research and Forecasting (WRF) model operated by the University of Washington. Locations are listed from north to south. $\mathrm{WX}=$ WatchDog meteorological measurement station; $\mathrm{PM}_{2.5}=$ Met One Instruments, Inc. E-Sampler; RAWS = remote automated weather station; WS = wind speed; WD = wind direction. Calm winds indicate values under $0.25 \mathrm{~m} \cdot \mathrm{s}^{-1}$.

\begin{tabular}{|c|c|c|c|c|c|c|}
\hline Location & $\begin{array}{c}\text { Station } \\
\text { Type }\end{array}$ & Time & $\begin{array}{l}\text { WS Bias } \\
\left(\mathrm{m} \cdot \mathrm{s}^{-1}\right)\end{array}$ & $\begin{array}{l}\text { WS Error } \\
\left(\mathrm{m} \cdot \mathrm{s}^{-1}\right)\end{array}$ & $\begin{array}{l}\text { WD Error } \\
\left({ }^{\circ}\right)\end{array}$ & \% Calm \\
\hline \multirow{2}{*}{$\begin{array}{l}\text { Sisters } \\
\text { Ranger } \\
\text { Station }\end{array}$} & WX & Day & 3.22 & 3.22 & Calm & $63 \%$ \\
\hline & & Night & Calm & Calm & Calm & $100 \%$ \\
\hline \multirow{2}{*}{$\begin{array}{l}\text { Bridges } \\
\text { Boys } \\
\text { Academy }\end{array}$} & WX & Day & 0.81 & 0.84 & 28.52 & $0 \%$ \\
\hline & & Night & 1.68 & 1.68 & 8.96 & $43 \%$ \\
\hline \multirow[t]{2}{*}{$\begin{array}{l}\text { Cascade } \\
\text { Academy }\end{array}$} & $W X$ & Day & 3.63 & 3.63 & 30.81 & $0 \%$ \\
\hline & & Night & Calm & Calm & Calm & $100 \%$ \\
\hline
\end{tabular}


Table A5. Cont.

\begin{tabular}{|c|c|c|c|c|c|c|}
\hline Location & $\begin{array}{c}\text { Station } \\
\text { Type }\end{array}$ & Time & $\begin{array}{c}\text { WS Bias } \\
\left(\mathrm{m} \cdot \mathrm{s}^{-1}\right)\end{array}$ & $\begin{array}{l}\text { WS Error } \\
\left(\mathrm{m} \cdot \mathrm{s}^{-1}\right)\end{array}$ & $\begin{array}{l}\text { WD Error } \\
\left({ }^{\circ}\right)\end{array}$ & $\%$ Calm \\
\hline \multirow[t]{2}{*}{$\begin{array}{l}\text { Miller } \\
\text { Elementary }\end{array}$} & \multirow[t]{2}{*}{$W X$} & Day & 3.04 & 3.04 & 28.52 & $0 \%$ \\
\hline & & Night & Calm & Calm & Calm & $100 \%$ \\
\hline \multirow[t]{2}{*}{$\begin{array}{l}\text { Tumalo } \\
\text { Ridge }\end{array}$} & \multirow[t]{2}{*}{ RAWS } & Day & 1.61 & 1.61 & 18.25 & $0 \%$ \\
\hline & & Night & 0.82 & 0.82 & 42.75 & $0 \%$ \\
\hline \multirow{2}{*}{$\begin{array}{l}\text { Cascade } \\
\text { Middle } \\
\text { School }\end{array}$} & \multirow[t]{2}{*}{$\mathrm{PM}_{2.5}$} & Day & 1.65 & 1.65 & 35.82 & $0 \%$ \\
\hline & & Night & 1.02 & 1.02 & 121.68 & $0 \%$ \\
\hline \multirow[t]{2}{*}{ Lava Butte } & \multirow[t]{2}{*}{ RAWS } & Day & 3.87 & 3.87 & 23.98 & $0 \%$ \\
\hline & & Night & 0.64 & 0.64 & Calm & $71 \%$ \\
\hline \multirow[t]{2}{*}{ Sunriver } & \multirow[t]{2}{*}{$\mathrm{PM}_{2.5}$} & Day & 0.38 & 0.38 & 6.97 & $0 \%$ \\
\hline & & Night & 1.80 & 1.80 & 99.23 & $0 \%$ \\
\hline \multirow{2}{*}{$\begin{array}{l}\text { Round } \\
\text { Mountain }\end{array}$} & \multirow[t]{2}{*}{ RAWS } & Day & 2.44 & 2.44 & 35.94 & $0 \%$ \\
\hline & & Night & -1.46 & 1.46 & 128.72 & $0 \%$ \\
\hline
\end{tabular}

Table A6. Wind speed bias and error, wind direction error, and percentage of calm observations for day and night on 6 June 2015. Model data are from the 4-km-resolution Weather Research and Forecasting (WRF) model operated by the University of Washington. Locations are listed from north to south. $\mathrm{WX}=$ WatchDog meteorological measurement station; $\mathrm{PM}_{2.5}=$ Met One Instruments, Inc. E-Sampler; RAWS = remote automated weather station; $\mathrm{WS}=$ wind speed; $\mathrm{WD}=$ wind direction. Calm winds indicate values under $0.25 \mathrm{~m} \cdot \mathrm{s}^{-1}$.

\begin{tabular}{|c|c|c|c|c|c|c|}
\hline Location & $\begin{array}{c}\text { Station } \\
\text { Type }\end{array}$ & Time & $\begin{array}{l}\text { WS Bias } \\
\left(\mathrm{m} \cdot \mathrm{s}^{-1}\right)\end{array}$ & $\begin{array}{l}\text { WS Error } \\
\left(\mathrm{m} \cdot \mathrm{s}^{-1}\right)\end{array}$ & $\begin{array}{l}\text { WD Error } \\
\left({ }^{\circ}\right)\end{array}$ & $\%$ Calm \\
\hline \multirow{2}{*}{$\begin{array}{l}\text { Sisters } \\
\text { Ranger } \\
\text { Station }\end{array}$} & \multirow[t]{2}{*}{$W X$} & Day & 2.14 & 2.14 & 58.62 & $38 \%$ \\
\hline & & Night & Calm & Calm & Calm & $100 \%$ \\
\hline \multirow{2}{*}{$\begin{array}{l}\text { Bridges } \\
\text { Boys } \\
\text { Academy }\end{array}$} & \multirow[t]{2}{*}{ WX } & Day & 1.29 & 1.29 & 37.76 & $0 \%$ \\
\hline & & Night & Calm & Calm & Calm & $100 \%$ \\
\hline \multirow[t]{2}{*}{$\begin{array}{l}\text { Cascade } \\
\text { Academy }\end{array}$} & \multirow[t]{2}{*}{ WX } & Day & 1.95 & 1.95 & 45.75 & $13 \%$ \\
\hline & & Night & Calm & Calm & Calm & $100 \%$ \\
\hline \multirow[t]{2}{*}{$\begin{array}{l}\text { Miller } \\
\text { Elementary }\end{array}$} & \multirow[t]{2}{*}{ WX } & Day & 2.66 & 2.66 & 25.99 & $0 \%$ \\
\hline & & Night & Calm & Calm & Calm & $100 \%$ \\
\hline \multirow{2}{*}{$\begin{array}{l}\text { Tumalo } \\
\text { Ridge }\end{array}$} & \multirow[t]{2}{*}{ RAWS } & Day & 0.93 & 1.03 & 22.56 & $0 \%$ \\
\hline & & Night & -0.34 & 0.57 & 67.89 & $0 \%$ \\
\hline \multirow{2}{*}{$\begin{array}{l}\text { Cascade } \\
\text { Middle } \\
\text { School }\end{array}$} & $\mathrm{PM}_{2.5}$ & Day & 1.00 & 1.00 & 39.05 & $0 \%$ \\
\hline & & Night & -0.19 & 0.91 & 88.94 & $0 \%$ \\
\hline
\end{tabular}


Table A6. Cont.

\begin{tabular}{|c|c|c|c|c|c|c|}
\hline Location & $\begin{array}{c}\text { Station } \\
\text { Type }\end{array}$ & Time & $\begin{array}{c}\text { WS Bias } \\
\left(\mathrm{m} \cdot \mathrm{s}^{-1}\right)\end{array}$ & $\begin{array}{l}\text { WS Error } \\
\left(\mathrm{m} \cdot \mathrm{s}^{-1}\right)\end{array}$ & $\begin{array}{l}\text { WD Error } \\
\left({ }^{\circ}\right)\end{array}$ & $\%$ Calm \\
\hline \multirow[t]{2}{*}{ Lava Butte } & \multirow[t]{2}{*}{ RAWS } & Day & 2.28 & 2.28 & 15.47 & $0 \%$ \\
\hline & & Night & -0.15 & 0.36 & 69.37 & $14 \%$ \\
\hline \multirow[t]{2}{*}{ Sunriver } & \multirow[t]{2}{*}{$\mathrm{PM}_{2.5}$} & Day & 0.10 & 0.57 & 9.15 & $0 \%$ \\
\hline & & Night & 0.30 & 0.78 & 85.12 & $0 \%$ \\
\hline \multirow{2}{*}{$\begin{array}{l}\text { Round } \\
\text { Mountain }\end{array}$} & \multirow[t]{2}{*}{ RAWS } & Day & 1.70 & 1.70 & 48.04 & $0 \%$ \\
\hline & & Night & -0.88 & 1.08 & 76.09 & $0 \%$ \\
\hline
\end{tabular}

\section{References}

1. Johnson, E.; Miyanishi, K. Forest Fires: Behavior and Ecological Effects; Academic Press: Cambridge, MA, USA, 2001; ISBN 0080506747.

2. Rorig, M.; Solomon, R.; Krull, C.; Peterson, J.; Ruthford, J.; Potter, B. Analysis of meteorological conditions for the Yakima Smoke Intrusion case study, 28 September 2009. USDA For. Serv. Res. Pap. PNW-RP 2013, 1-32. [CrossRef]

3. Garcia-Menendez, F.; Hu, Y.; Odman, M.T. Simulating smoke transport from wildland fires with a regional-scale air quality model: Sensitivity to uncertain wind fields. J. Geophys. Res. Atmos. 2013, 118, 6493-6504. [CrossRef]

4. Ottmar, R.D.; Hiers, J.K.; Butler, B.W.; Clements, C.B.; Dickinson, M.B.; Hudak, A.T.; O’Brien, J.J.; Potter, B.E.; Rowell, E.M.; Strand, T.M. Measurements, datasets and preliminary results from the RxCADRE project-2008, 2011 and 2012. Int. J. Wildl. Fire 2016, 25, 1-9. [CrossRef]

5. Bowman, D.M.J.S.; Balch, J.K.; Artaxo, P.; Bond, W.J.; Carlson, J.M.; Cochrane, M.A.; D'Antonio, C.M.; DeFries, R.S.; Doyle, J.C.; Harrison, S.P. Fire in the Earth system. Science (80-.) 2009, 324, 481-484. [CrossRef] [PubMed]

6. Covington, W.W.; Moore, M.M. Southwestern ponderosa forest structure: Changes since Euro-American settlement. J. For. 1994, 92, 39-47.

7. Hessburg, P.F.; Agee, J.K.; Franklin, J.F. Dry forests and wildland fires of the inland Northwest USA: Contrasting the landscape ecology of the pre-settlement and modern eras. For. Ecol. Manag. 2005, 211, 117-139. [CrossRef]

8. Graham, R.; McCaffrey, S.; Jain, T. Science basis for changing forest structure to modify wildfire behavior and severity. In General Technical Reports; RMRS-GTR-120; U.S. Department of Agriculture, Forest Service, Rocky Mountain Research Station: Fort Collins, CO, USA, 2004; 43p. [CrossRef]

9. Covington, W.W.; Fule, P.Z.; Moore, M.M.; Hart, S.C.; Kolb, T.E.; Mast, J.N.; Sackett, S.S.; Wagner, M.R. Restoring ecosystem health in ponderosa pine forests of the Southwest. J. For. 1997, 95, 23.

10. Agee, J.K.; Edmonds, R.L.; Gara, R.I. Forest Health and Protection, 2nd ed.; Waveland Press: Long Grove, IL, USA, 2010.

11. Mitchell, S.R.; Harmon, M.E.; O'connell, K.E.B. Forest fuel reduction alters fire severity and long-term carbon storage in three Pacific Northwest ecosystems. Ecol. Appl. 2009, 19, 643-655. [CrossRef]

12. Delfino, R.J.; Staimer, N.; Tjoa, T.; Gillen, D.L.; Polidori, A.; Arhami, M.; Kleinman, M.T.; Vaziri, N.D.; Longhurst, J.; Sioutas, C. Air pollution exposures and circulating biomarkers of effect in a susceptible population: Clues to potential causal component mixtures and mechanisms. Environ. Health Perspect. 2009, 117, 1232. [CrossRef]

13. Morgan, G.; Sheppeard, V.; Khalaj, B.; Ayyar, A.; Lincoln, D.; Jalaludin, B.; Beard, J.; Corbett, S.; Lumley, T. Effects of bushfire smoke on daily mortality and hospital admissions in Sydney, Australia. Epidemiology 2010, 21, 47-55. [CrossRef]

14. Rappold, A.G.; Stone, S.L.; Cascio, W.E.; Neas, L.M.; Kilaru, V.J.; Carraway, M.S.; Szykman, J.J.; Ising, A.; Cleve, W.E.; Meredith, J.T.; et al. Peat bog wildfire smoke exposure in rural North Carolina is associated with cardiopulmonary emergency department visits assessed through syndromic surveillance. (Research)(Report). Environ. Health Perspect. 2011, 119, 1415. [CrossRef] [PubMed] 
15. Kochi, I.; Donovan, G.H.; Champ, P.A.; Loomis, J.B. The economic cost of adverse health effects from wildfire-smoke exposure: A review. Int. J. Wildl. Fire 2010, 19, 803-817. [CrossRef]

16. Naeher, L.P.; Brauer, M.; Lipsett, M.; Zelikoff, J.T.; Simpson, C.D.; Koenig, J.Q.; Smith, K.R. Woodsmoke health effects: A review. Inhal. Toxicol. 2007, 19, 67-106. [CrossRef] [PubMed]

17. Xing, Y.-F.; Xu, Y.-H.; Shi, M.-H.; Lian, Y.-X. The impact of $\mathrm{PM}_{2.5}$ on the human respiratory system. J. Thorac. Dis. 2016, 8, E69. [PubMed]

18. Clean Air Act; United States; 1963. Available online: https://www.epa.gov/clean-air-act-overview/clean-airact-text (accessed on 15 August 2019).

19. Andrews, P.L. Modeling Wind Adjustment Factor and Midflame Wind Speed for Rothermel's Surface Fire Spread Model; Gen. Tech. Rep. RMRS-GTR-266; Department of Agriculture, Forest Service, Rocky Mountain Research Station: Fort Collin, CO, USA, 2012; Volume 266, 39p.

20. Hardy, C.C.; Ottmar, R.D.; Peterson, J.L.; Core, J.E.; Seamon, P. Smoke Management Guide for Prescribed and Wildland Fire: 2001 Edition; PMS 420-2. NFES 1279; National Wildfire Coodination Group: Boise, ID, USA, $2001 ; 226$.

21. Characterization of Smoke Incidents or Intrusions. Oregon Administrative Rules, Division 48, Chapter 629, Oregon Secretary of State. 2007. Available online: https://oregon.public.law/rules/oar_629-048-0110 (accessed on 15 August 2019).

22. Strand, T.M.; Larkin, N.; Craig, K.; Raffuse, S.; Sullivan, D.; Solomon, R.; Rorig, M.; Wheeler, N.; Pryden, D. Analyses of BlueSky Gateway $\mathrm{PM}_{2.5}$ predictions during the 2007 southern and 2008 northern California fires. J. Geophys. Res. 2012, 117. [CrossRef]

23. Kochanski, A.K.; Jenkins, M.A.; Mandel, J.; Beezley, J.D.; Clements, C.B.; Krueger, S. Evaluation of WRF-SFIRE performance with field observations from the FireFlux experiment. arXiv 2012. [CrossRef]

24. Hiers, J.K.; Ottmar, R.; Butler, B.W.; Clements, C.; Vihnanek, R.; Dickinson, M.B.; O’Brien, J. An overview of the prescribed fire combustion and atmospheric dynamics research experiment (Rx-CADRE). In Proceedings of the 4th International Fire Ecology and Management Congress: Fire as a Global Process, Savannah, GA, USA, 30 November-4 December 2009; Volume 30.

25. Burning \& Smoke Management. Oregon Department of Forestry. Available online: https://www.oregon.gov/ odf/fire/pages/burn.aspx (accessed on 15 August 2019).

26. Lighthall, K. Greater Bend Community Wildfire Protection Plan. 2006. Available online: http://www. projectwildfire.org/wp-content/uploads/2016/02/Bend-CWPP-Full-Final.pdf (accessed on 15 August 2019).

27. Bradshaw, L.; McCormick, E. FireFamily Plus User's Guide, Version 2.0; Gen. Tech. Rep. RMRS-GTR-67; US Department of Agriculture, Forest Service, Rocky Mountain Research Station: Ogden, UT, USA, 2000; Volume 67. [CrossRef]

28. Ottmar, R.; Restiano, J.; Vihnanek, R.; Burcke, C. Final Report: Identifying Fuelbed Components that Contribute to Smoldering Consumption to Improve Smoke Management Decisions for Prescribed Fire Application East of the Cascades in Oregon and Washington; USDA Forest Service, Pacific Northwest Research Station: Seattle, WA, USA, 2014.

29. Holder, A.L.; Hagler, G.S.W.; Aurell, J.; Hays, M.D.; Gullett, B.K. Particulate matter and black carbon optical properties and emission factors from prescribed fires in the southeastern United States. J. Geophys. Res. Atmos. 2016, 121, 3465-3483. [CrossRef]

30. Martinsson, J.; Eriksson, A.C.; Nielsen, I.E.; Malmborg, V.B.; Ahlberg, E.; Andersen, C.; Lindgren, R.; Nystrom, R.; Nordin, E.Z.; Brune, W.H. Impacts of combustion conditions and photochemical processing on the light absorption of biomass combustion aerosol. Environ. Sci. Technol. 2015, 49, 14663-14671. [CrossRef]

31. Hand, J.L.; Malm, W.C. Review of aerosol mass scattering efficiencies from ground-based measurements since 1990. J. Geophys. Res. Atmos. 2007, 112. [CrossRef]

32. Levin, E.J.T.; McMeeking, G.R.; Carrico, C.M.; Mack, L.E.; Kreidenweis, S.M.; Wold, C.E.; Moosmüller, H.; Arnott, W.P.; Hao, W.M.; Collett Jr, J.L. Biomass burning smoke aerosol properties measured during Fire Laboratory at Missoula Experiments (FLAME). J. Geophys. Res. Atmos. 2010, 115. [CrossRef]

33. Jung, C.H.; Um, J.; Bae, S.Y.; Yoon, Y.J.; Lee, S.S.; Lee, J.Y.; Kim, Y.P. Analytic expression for the aerosol mass efficiencies for polydispersed accumulation mode. Aerosol Air Qual. Res. 2018, 18, 1503. [CrossRef]

34. Hosseini, S.; Urbanski, S.P.; Dixit, P.; Qi, L.; Burling, I.R.; Yokelson, R.J.; Johnson, T.J.; Shrivastava, M.; Jung, H.S.; Weise, D.R. Laboratory characterization of PM emissions from combustion of wildland biomass fuels. J. Geophys. Res. Atmos. 2013, 118, 9914-9929. [CrossRef] 
35. Larkin, N.K.; O’Neill, S.M.; Solomon, R.; Raffuse, S.; Strand, T.; Sullivan, D.C.; Krull, C.; Rorig, M.; Peterson, J.; Ferguson, S.A. The BlueSky smoke modeling framework. Int. J. Wildl. Fire 2009, 18, 906-920. [CrossRef]

36. Prichard, S.J.; Andreu, A.; Eagle, P.; Swedin, K.; Sandberg, D.V.; Ottmar, R.D.; Eberhardt, E. Fuel characteristic classification system version 3.0: Technical documentation. USDA For. Serv. Gen. Tech. Rep. PNW-GTR 2013, 1-79. [CrossRef]

37. Larkin, N.K.; Strand, T.M.; Drury, S.A.; Raffuse, S.M.; Solomon, R.C.; O'Neill, S.M.; Wheeler, N.; Huang, S.; Roring, M.; Hafner, H.R. Phase 1 of the Smoke and Emissions Model Intercomparison Project (SEMIP): Creation of SEMIP and Evaluation of Current Models; Final Report to the Joint Fire Science Program, Project \#08-1-6-10; Joint Fire Science Program: Boise, ID, USA, 2012. Available online: https://www.firescience.gov/projects/081-6-10/project/08-1-6-10_final_report.pdf (accessed on 15 August 2019).

38. Michalakes, J.; Chen, S.; Dudhia, J.; Hart, L.; Klemp, J.; Middlecoff, J.; Skamarock, W. Development of a next-generation regional weather research and forecast model. In Developments in Teracomputing; World Scientific: Singapore, 2001; pp. 269-276.

39. Skamarock, W.; Klemp, J.; Dudhia, J.; Gill, D.; Barker, D.; Wang, W. A Description of the Advanced Research WRF Version 2; Mesoscale and Microscale Meteorology Division, National Center for Atmospheric Research: Boulder, CO, USA, 2005.

40. Stein, A.F.; Draxler, R.R.; Rolph, G.D.; Stunder, B.J.B.; Cohen, M.D.; Ngan, F. NOAA'S HYSPLIT atmospheric transport and dispersion modeling system. Bull. Am. Meteorol. Soc. 2015, 96, 2059-2078. [CrossRef]

41. Draxler, R.R.; Hess, G.D. An overview of the HYSPLIT_4 modelling system for trajectories. Aust. Meteorol. Mag. 1998, 47, 295-308.

42. Mass, C.F.; Albright, M.; Ovens, D.; Steed, R.; MacIver, M.; Grimit, E.; Eckel, T.; Lamb, B.; Vaughan, J.; Westrick, K. Regional environmental prediction over the Pacific Northwest. Bull. Am. Meteorol. Soc. 2003, 84, 1353-1366. [CrossRef]

43. Rogers, E.; DiMego, G.; Black, T.; Ek, M.; Ferrier, B.; Gayno, G.; Janjic, Z.; Lin, Y.; Pyle, M.; Wong, V.; et al. The NCEP North American Mesoscale Modeling System: Recent changes and Future Plans. In Proceedings of the 23rd Conference on Weather Analysis and Forecasting/19th Conference on Numerical Weather Prediction, Omaha, NE, USA, 1-5 June 2009.

44. Albini, F.A. Estimating Wildfire Behavior and Effects; Gen. Tech. Rep. INT-GTR-30; Department of Agriculture, Forest Service, Intermountain Forest and Range Experiment Station: Ogden, UT, USA, 1976; Volume 30, 92p.

45. Rothermel, R.C. A Mathematical Model for Predicting Fire Spread in Wildland Fuels; Res. Pap. INT-115; Department of Agriculture, Intermountain Forest and Range Experiment Station: Ogden, UT, USA, 1972; Volume 115, 40p.

46. Paxon, J. Remember Los Alamos: The Cerro Grande Fire. Fire Manag. Today 2000, 60, 9-14.

47. Buck, C.C.; Schroeder, M.J. Fire Weather: A Guide for Application of Meteorological Information to Forest Fire Control Operations; Buck, C.C., Ed.; Department of Agriculture, Forest Service: Washington, DC, USA, 1970.

48. Urbanski, S. Wildland fire emissions, carbon, and climate: Emission factors. For. Ecol. Manag. 2014, 317, 51-60. [CrossRef]

49. Hoadley, J.L.; Rorig, M.L.; Bradshaw, L.; Ferguson, S.A.; Westrick, K.J.; Goodrick, S.L.; Werth, P. Evaluation of MM5 model resolution when applied to prediction of National Fire Danger Rating indexes. Int. J. Wildl. Fire 2006, 15, 147-154. [CrossRef]

50. Ngan, F.; Kim, H.; Lee, P.; Al-Wali, K.; Dornblaser, B. A study of nocturnal surface wind speed overprediction by the WRF-ARW model in southeastern Texas. J. Appl. Meteorol. Climatol. 2013, 52, 2638-2653. [CrossRef]

51. Draxl, C.; Clifton, A.; Hodge, B.-M.; McCaa, J. The wind integration national dataset (wind) toolkit. Appl. Energy 2015, 151, 355-366. [CrossRef]

52. Cheng, W.Y.Y.; Steenburgh, W.J. Evaluation of surface sensible weather forecasts by the WRF and the Eta models over the western United States. Weather Forecast. 2005, 20, 812-821. [CrossRef]

53. Mohan, M.; Bhati, S. Analysis of WRF model performance over subtropical region of Delhi, India. Adv. Meteorol. 2011, 2011. [CrossRef]

54. Hanna, S.R.; Reen, B.; Hendrick, E.; Santos, L.; Stauffer, D.; Deng, A.; McQueen, J.; Tsidulko, M.; Janjic, Z.; Jovic, D. Comparison of observed, MM5 and WRF-NMM model-simulated, and HPAC-assumed boundary-layer meteorological variables for 3 days during the IHOP field experiment. Bound. Layer Meteorol. 2010, 134, 285-306. [CrossRef] 
55. Borge, R.; Alexandrov, V.; Del Vas, J.J.; Lumbreras, J.; Rodriguez, E. A comprehensive sensitivity analysis of the WRF model for air quality applications over the Iberian Peninsula. Atmos. Environ. 2008, 42, 8560-8574. [CrossRef]

56. Kwun, J.H.; Kim, Y.-K.; Seo, J.-W.; Jeong, J.H.; You, S.H. Sensitivity of MM5 and WRF mesoscale model predictions of surface winds in a typhoon to planetary boundary layer parameterizations. Nat. Hazards 2009, 51, 63-77. [CrossRef]

57. Ruiz, J.J.; Saulo, C.; Nogués-Paegle, J. WRF model sensitivity to choice of parameterization over South America: Validation against surface variables. Mon. Weather Rev. 2010, 138, 3342-3355. [CrossRef]

58. Goodrick, S.L.; Achtemeier, G.L.; Larkin, N.K.; Liu, Y.; Strand, T.M. Modelling smoke transport from wildland fires: A review. Int. J. Wildl. Fire 2013, 22, 83-94. [CrossRef]

59. Seto, D.; Strand, T.M.; Clements, C.B.; Thistle, H.; Mickler, R. Wind and plume thermodynamic structures during low-intensity subcanopy fires. Agric. For. Meteorol. 2014, 198, 53-61. [CrossRef]

60. Heilman, W.E.; Clements, C.B.; Seto, D.; Bian, X.; Clark, K.L.; Skowronski, N.S.; Hom, J.L. Observations of fire-induced turbulence regimes during low-intensity wildland fires in forested environments: Implications for smoke dispersion. Atmos. Sci. Lett. 2015, 16, 453-460. [CrossRef]

(C) 2019 by the authors. Licensee MDPI, Basel, Switzerland. This article is an open access article distributed under the terms and conditions of the Creative Commons Attribution (CC BY) license (http://creativecommons.org/licenses/by/4.0/). 